\title{
Sulfonium Ion Derivatization, Isobaric Stable Isotope Labeling and Data Dependent CID- and ETD-MS/MS for Enhanced Phosphopeptide Quantitation, Identification and Phosphorylation Site Characterization
}

\author{
Yali Lu, ${ }^{1}$ Xiao Zhou, ${ }^{1}$ Paul M. Stemmer, ${ }^{2}$ Gavin E. Reid ${ }^{1,3}$ \\ ${ }^{1}$ Department of Chemistry, Michigan State University, 229 Chemistry Building, Michigan State University, East Lansing, MI, \\ 48824, USA \\ ${ }^{2}$ Institute of Environmental Health Sciences, Wayne State University, Detroit, MI, USA \\ ${ }^{3}$ Department of Biochemistry and Molecular Biology, Michigan State University, East Lansing, MI, USA
}

\begin{abstract}
An amine specific peptide derivatization strategy involving the use of novel isobaric stable isotope encoded 'fixed charge' sulfonium ion reagents, coupled with an analysis strategy employing capillary HPLC, ESI-MS, and automated data dependent ion trap CID-MS/MS, -MS ${ }^{3}$, and/or ETDMS/MS, has been developed for the improved quantitative analysis of protein phosphorylation, and for identification and characterization of their site(s) of modification. Derivatization of 50 synthetic phosphopeptides with $S, S^{\prime}$-dimethylthiobutanoylhydroxysuccinimide ester iodide (DMBNHS), followed by analysis using capillary HPLC-ESI-MS, yielded an average 2.5 -fold increase in ionization efficiencies and a significant increase in the presence and/or abundance of higher charge state precursor ions compared to the non-derivatized phosphopeptides. Notably, $44 \%$ of the phosphopeptides (22 of 50 ) in their underivatized states yielded precursor ions whose maximum charge states corresponded to +2 , while only $8 \%$ ( 4 of 50 ) remained at this maximum charge state following DMBNHS derivatization. Quantitative analysis was achieved by measuring the abundances of the diagnostic product ions corresponding to the neutral losses of 'light' $\left(\mathrm{S}\left(\mathrm{CH}_{3}\right)_{2}\right)$ and 'heavy' $\left(\mathrm{S}\left(\mathrm{CD}_{3}\right)_{2}\right)$ dimethylsulfide exclusively formed upon CID-MS/MS of isobaric stable isotope labeled forms of the DMBNHS derivatized phosphopeptides. Under these conditions, the phosphate group stayed intact. Access for a greater number of peptides to provide enhanced phosphopeptide sequence identification and phosphorylation site characterization was achieved via automated data-dependent CID-MS ${ }^{3}$ or ETD-MS/MS analysis due to the formation of the higher charge state precursor ions. Importantly, improved sequence coverage was observed using ETD-MS/MS following introduction of the sulfonium ion fixed charge, but with no detrimental effects on ETD fragmentation efficiency.
\end{abstract}

Key words: Phosphopeptide fragmentation, Collision induced dissociation (CID), Electron transfer dissociation (ETD), Fixed charge

Electronic supplementary material The online version of this article (doi:10.1007/s13361-011-0190-0) contains supplementary material, which is available to authorized users.

Correspondence to: Gavin E. Reid; e-mail: reid@chemistry.msu.edu

\section{Introduction}

Comprehensive phosphoproteome analysis requires the identification of phosphorylated proteins, localization of the specific sites of phosphorylation within these proteins, 
and quantification of the phosphorylation site occupancies under the specific biological environment [1-6]. To date, the success of such strategies have undoubtedly been facilitated by the application of tandem mass spectrometry (MS/MS) and associated sample fractionation/enrichment methods for phosphopeptide identification, characterization, and quantification [7-9]. However, when multiple potential sites of phosphorylation exist within a peptide sequence, unambiguous phosphorylation site characterization remains a considerable challenge.

Typically, phosphorylation sites are identified by MS/ $\mathrm{MS}$ and/or $-\mathrm{MS}^{3}$ using either collision induced dissociation (CID) or electron transfer dissociation (ETD) as the ion activation techniques $[8,9]$. Unfortunately, unambiguous phosphorylation site localization by using CID-MS/ MS strategies in ion trap mass spectrometers (where ion activation occurs in the ms timescale) may be hindered by dominant facile neutral losses of $80 \mathrm{Da}\left(\mathrm{HPO}_{3}\right)$ or $98 \mathrm{Da}$ $\left(\mathrm{H}_{3} \mathrm{PO}_{4}\right)$ from the phosphoaminoacid side chain [9-11], or intramolecular phosphate group 'scrambling' [12], due to the formation of strong intramolecular hydrogen bonding interactions between the phosphate group and the side chain of a protonated arginine or lysine residue that lower the barriers to side chain loss or rearrangement, particularly under 'non-mobile' or 'partially mobile' precursor ion proton mobility conditions. Numerous groups have employed ion trap CID-MS ${ }^{3}$ to subject the initial $98 \mathrm{Da}$ neutral loss product ions to further dissociation to obtain additional structural information for phosphorylation site characterization [13-18]. However, competing pathways for the loss of 98 Da (i.e.; the combined losses of $\mathrm{HPO}_{3}$ and $\mathrm{H}_{2} \mathrm{O}$ from the phosphoamino acid side chain and an unmodified serine or threonine residue within the sequence, respectively), have been reported [12]. Therefore, as the extent to which this competing pathway is operative cannot be known a priori, $\mathrm{MS}^{3}$ methods may unfortunately not be used to localize phosphorylation site (s) without some ambiguity. To minimize the limitations associated with ion trap CID-MS/MS of protonated phosphopeptides therefore, precursor ions selected for dissociation should preferentially be in a 'mobile' protonation state (i.e.; charge states $\geq+2$ for peptides formed by proteolysis with trypsin). ETD has an improved ability to localize phosphate groups [19-25], as no losses involving the phosphate side chain or phosphate group 'scrambling' are observed [9, 12, 19-25]. However, the effectiveness of ETD-MS/MS can be limited in that it also optimally requires the precursor ions to be highly multiply-charged (i.e.; $\geq 3+$, where the ion/ion reaction cross-section is sufficiently large for efficient dissociation to occur) [1921]. Finally, due to their acidic nature, there is the potential that ionization efficiencies and maximum precursor ion charge states of phosphopeptides can be lower compared to their nonphosphorylated counterparts, thereby limiting the sensitivity for their detection, and restricting the applicability of CIDand ETD-MS/MS to only a partial subset of the phosphopep- tides expected to be found within complex phosphoproteomic mixtures [26-29].

To overcome these limitations, significant effort has recently been extended toward developing approaches to increase the ionization and charge states of phosphopeptide ions, and/or to alter their gas-phase fragmentation behaviors, for improved CID- and ETD-MS/MS performance. One approach has been to generate larger peptides capable of forming precursor ions by ESI that carry three or more positive charges, by using trypsin under conditions of limited proteolysis [25] or by using proteolytic enzymes with limited cleavage specificity, such as Lys-C [21, 22, 30], Glu-C [22], or Lys-N [31]. Another involves the addition of 'supercharging' reagents such as low concentrations of $\mathrm{m}$ nitrobenzyl alcohol or sulfolane to the chromatographic elution or ESI solvents [32, 33], with a subsequent increase in peptide precursor ion charge states, ETD fragmentation efficiency, and database search scores for protein identification [32]. Finally, a variety of chemical derivatization strategies designed to introduce additional basic sites or fixed positive charges (e.g.; ammonium or phosphonium ion functional groups) have been developed and widely applied to proteome and phosphoproteome analysis studies using ESI-MS and CID- and/or ETD-MS/MS [34-48]. For example, Vasicek and Brodbelt have reported the formation of higher charge states and improved ETD-MS/MS fragmentation efficiency and sequence coverage upon alkylation of cysteine containing peptides with 3-(acrylamidopropyl)trimethylammonium chloride [37]. For phosphopeptides, Xu et al. [39] and Zhang et al. [40] reported the use of 1-(2pyrimidyl)piperazine for derivatization of the carboxyl groups, yielding enhanced ionization efficiencies and a shift toward higher peptide precursor ion charge states for subsequent ETD-MS/MS. The use of chemical derivatization is also attractive from the standpoint of being able to incorporate stable isotope labels for subsequent differential quantitative phosphoproteome analysis, by measuring the relative abundances of "light" and "heavy" labeled peptide precursor or product ions following acquisition of the ESIMS or -MS/MS spectra, respectively [42-47]. However, while Thingholm et al. also reported significantly greater charging in ESI when using the commercially available isobaric Tag for Relative and Absolute Quantitation (iTRAQ) [42] and tandem mass tag (TMT) [43] reagents, a reduction in phosphopeptide identification efficiency was noted when using these tags with ion trap CID-MS/MS multistage activation and beam type (i.e., HCD) CID-MS/ MS for quantitative analysis [48]. Pichler et al. also reported reduced CID-MS/MS identification rates using 8plex iTRAQ and 6-plex TMT reagents compared with the 4-plex iTRAQ reagent [49]. Furthermore, while ion trap pulsed $\mathrm{Q}$ dissociation (PQD) or HCD fragmentation is typically employed for detection of the low $\mathrm{m} / \mathrm{z}$ iTRAQ reporter ions for quantitation $[50,51]$, thereby overcoming the low mass cutoff limitation inherent to performing conventional CIDMS/MS in ion trap mass spectrometers, the fragmentation 
pathways for formation of the reporter ions using CID (as well as for ETD) are in competition with those for peptide backbone cleavage. Thus, when the reporter ions are formed at low relative abundance, the ability to perform accurate quantitation may be compromised. Finally, while ETD-MS/MS has been reported to identify a larger number of unique phosphopeptides than CID [23], use of the 4-plex iTRAQ reagent produces product ions that allow for only three channels of quantification, while peptides labeled with 8-plex iTRAQ tags produce reporter ions for only five channels of quantification $[52,53]$. In the latter case, CID-MS ${ }^{3}$ of a characteristic ETD product ion at $\mathrm{m} / \mathrm{z} 322$ can be used to provide all eight iTRAQ reporter ions [53]. To address each of these issues, a dual ion activation strategy can be employed, whereby pulsed Q-dissociation or beam type CID (HCD)-MS/MS of a mass selected precursor ion is first used for phosphopeptide quantification, followed by ETD-MS/ MS of the same precursor ion for sequence identification and phosphorylation site characterization $[54,55]$.

From the above discussion, it is clear that there remains room for the development of alternate chemical derivatization and associated analysis strategies that yield increased ionization efficiencies and precursor ion charge states, but without deleterious effects on the subsequent gas-phase fragmentation reactions and performance of CID- and ETDMS/MS-based dual ion activation workflows employed for phosphopeptide identification, characterization, and quantitation. We have previously reported that peptides containing 'fixed charge' dialkylsulfonium ion derivatives located on selected functional groups of certain amino acids, including the thioether side chain of methionine (formed by reaction with phenacylbromide under acidic conditions) [56-58], the thiol side chain of cysteine (formed by reaction with 3-([Nbromoacetamido]propyl)-methylphenacylsulfonium bromide (BAPMPS)) [59], or the amino side chain of lysine or peptide N-termini (formed by reaction with $S, S^{\prime}$-dimethylthiobutanoylhydroxysuccinimide ester (DMBNHS)) [60] all undergo the exclusive neutral loss(es) of dialkylsulfide groups upon CID-MS/MS, independently of the amino acid composition and precursor ion charge state (i.e.; proton mobility), thereby enabling the selective identification of derivatized peptides from within complex mixtures. The use of stable isotope-containing methionine-specific fixedcharge derivatization reagents (i.e.; ${ }^{2} \mathrm{H}_{5^{-}}$or ${ }^{13} \mathrm{C}_{6}$-labeled phenacylbromide) has previously been shown to facilitate the application of this approach toward the sensitive quantitative analysis of differential protein abundances, via ratiometric measurement of the relative abundances of the neutral loss product ions generated by CID-MS/MS dissociation of the light and heavy labeled peptide ions [56, 57]. Further structural interrogation of identified/quantified peptide ions has been achieved by subjecting the initial CIDMS/MS neutral loss product ion to CID-MS ${ }^{3}$ in a quadrupole ion trap mass spectrometer, or by energy resolved 'pseudo' $\mathrm{MS}^{3}$ in a triple quadrupole mass spectrometer [5660]. Notably, the dissociation of a 'monolinked' N-terminal sulfonium ion derivatized phosphoserine containing peptide formed by reaction with the cross-linking reagent $S$-methyl 5,5'-thiodipentanoylhydroxysuccinimide was recently shown to result in preferential fragmentation at the site of the fixed charge sulfonium ion, while the phosphate group remained intact, indicating that the specificity associated with sulfonium ion fragmentation is not affected by competing losses involving the potentially labile phosphate side chain [61].

Here, the use of novel isobaric stable isotope containing DMBNHS reagents for 'global' derivatization of peptide Nterminal amino and lysine functional groups, combined with ion trap CID-MS/MS analysis, are expected to serve as a useful strategy for enhanced phosphopeptide quantitative analysis, as the precursor ions of 'light' and 'heavy' isotope labeled sulfonium ion containing peptides will be exclusively converted to characteristic neutral loss products upon CID-MS/MS, i.e.; no 'dilution' of product ion abundance will be observed due to other competing fragmentation pathways. Furthermore, analogous to other reports involving the effects of fixed charge derivatization on ionization efficiencies and charge state distributions, the introduction of sulfonium ion fixed charge derivatives to phosphopeptides are expected to lead to improved ionization efficiencies and increase the abundance of high charge state precursor ions that are amenable to enhanced structural characterization and phosphorylation site localization by subsequently using automated data-dependent CID-MS ${ }^{3}$ or ETD-MS/MS analysis strategies.

\section{Materials and Methods}

\section{Materials}

All chemicals were analytical reagent (AR), or of a comparable or higher grade, and used without further purification. $N$-hydroxysuccinimide (NHS), $N, N^{\prime}$-dicyclohexylcarbodimide (DCC) and anhydrous dimethyl sulfoxide (DMSO) (stored over 3-Å molecular sieves) were purchased from Fluka (Buchs, Switzerland). Sodium methanethiolate, $\gamma$-butyrolactone, $\gamma$-butyrolactone- $\mathrm{d}_{6}$, 4-bromobutyric acid, thiourea, iodomethane- $\mathrm{d}_{3}$ and tris(hydroxymethyl)aminomethane (Tris) were from Sigma-Aldrich (St. Louis, MO, USA). Sodium hydroxide, sodium phosphate dibasic (crystal), potassium phosphate monobasic (crystal), magnesium sulfate (anhydrous), and formic acid (FA) were purchased from Spectrum Chemicals (Gardena, CA, USA). Sodium chloride, hydrochloric acid, and potassium hydroxide were purchased from Columbus Chemical Industries (Columbus, WI, USA). Potassium chloride, sulfuric acid, $N, N^{\prime}$-dimethyl formamide (DMF), and ethyl ether were purchased from Jade Scientific (Canton, MI, USA). Glacial acetic acid, dichloromethane, chloroform, methanol (anhydrous), ethanol, isopropyl alcohol, and ethyl acetate were purchased from Mallinckrodt Chemicals (Phillipsburg, NJ, USA). Iodomethane and acetonitrile were purchased from EMD Chemicals (San Diego, CA, USA). Trifluoroacetic acid 
(TFA) was purchased from Pierce (Rockford, IL, USA). All aqueous solutions were prepared by using deionized water purified by a Barnstead nanopure diamond purification system (Dubuque, IA, USA). The phosphoserine-containing peptide LFTGHPEpSLER was prepared 'in house' by manual stepwise Fmoc-based solid-phase peptide synthesis $[11,12]$. All other phosphopeptides were synthesized either by Sigma-Genosys (The Woodlands, TX, USA) or by JPT Peptide Technologies GmbH (Berlin, Germany), and were used without further purification.

\section{S,S'-Dimethylthiobutanoylhydroxysuccinimide Ester Iodide (DMBNHS)}

DMBNHS (Scheme 1) was synthesized as previously described [60], starting with preparation of methylthiobutyric acid from $\gamma$-butyrolactone, followed by activation to the NHS-ester and finally alkylation with iodomethane. The product was stored in the dark until further use.

\section{S,S'-Dimethylthio-d ${ }_{6}$-Butanoylhydroxysuccinimide Ester Iodide (D,-Light DMBNHS)}

Using the same strategy as previously described [60] for the synthesis of DMBNHS, to a solution of $2.72 \mathrm{~g}$ sodium methanethiolate $(34.9 \mathrm{mmol})$ in anhydrous DMSO $(26 \mathrm{~mL})$

$$
\mathrm{H}_{2} \mathrm{~N} \text { - Phosphopeptide }
$$
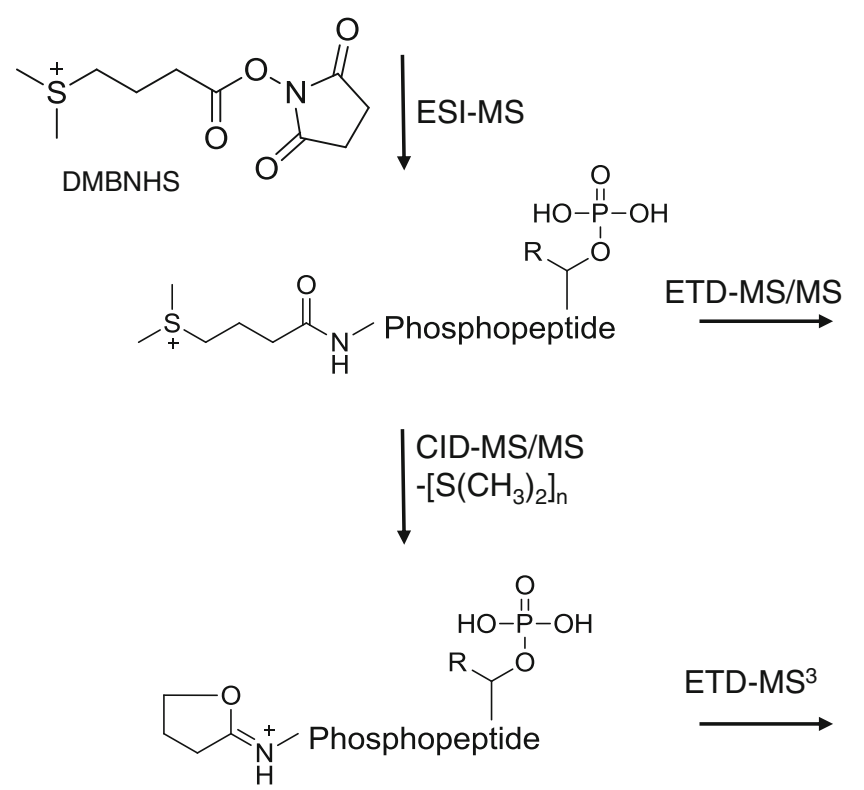

Scheme 1. Structure and general strategy for the solutionphase derivatization, ESI-MS, and data dependent CID- and ETD-MS/MS or $-\mathrm{MS}^{3}$ fragmentation of DMBNHS labeled phosphopeptides under a $\mathrm{N}_{2}$ atmosphere, $\gamma$-butyrolactone- $\mathrm{d}_{6}(2.0 \mathrm{~mL}$, $26.0 \mathrm{mmol}$ ) was added dropwise with stirring. The reaction was allowed to proceed at room temperature for $5 \mathrm{~d}$, then $65 \mathrm{~mL}$ of $1 \mathrm{M} \mathrm{HCl}$ was added to the resulting slurry. Following extraction with diethyl ether $(6 \times 40 \mathrm{~mL})$ and solvent evaporation under reduced pressure, the crude product was redissolved in $100 \mathrm{~mL}$ of dichloromethane and washed with $\mathrm{H}_{2} \mathrm{O}(3 \times 25 \mathrm{~mL})$. After drying with anhydrous $\mathrm{MgSO}_{4}$ and solvent evaporation in vacuo, a colorless oil of methylthio- $\mathrm{d}_{6}$-butyric acid $\mathbf{1}$ was obtained in $90 \%$ yield $(3.04 \mathrm{~g}) .{ }^{1} \mathrm{H}$ NMR $\left(500 \mathrm{MHz}, \mathrm{CDCl}_{3}\right): \delta 2.06(\mathrm{~s}$, $3 \mathrm{H}), 11.27$ (br, $1 \mathrm{H}) .{ }^{2} \mathrm{H}$ NMR (500 MHz, $\left.\mathrm{CDCl}_{3}\right): \delta 1.80(\mathrm{~s}$, 2H), 2.38 (s, 2H), 2.43 (s, broad, $2 \mathrm{H}) .{ }^{1} \mathrm{H}-\mathrm{NMR}$ spectra were obtained on a Varian Inova $500 \mathrm{MHz}$ instrument and are reported in parts per million ( $\mathrm{ppm}$ ) relative to the solvents resonances $(\delta)$, with coupling constants $(\mathrm{J})$ in Hertz $(\mathrm{Hz})$. Then, $1.40 \mathrm{~g}$ of acid $1(10.0 \mathrm{mmol})$ and $1.26 \mathrm{~g}$ of NHS $(11.0 \mathrm{mmol})$ were dissolved in 2:1 $\mathrm{vol} / \mathrm{vol}$ mixture of chloroform and dichloromethane $(30 \mathrm{~mL})$. After 5 -min stirring at room temperature, DCC $(2.27 \mathrm{~g}, 11.0 \mathrm{mmol})$ was added, and the resultant suspension was stirred overnight under a $\mathrm{N}_{2}$ atmosphere. The dicyclohexylurea (DCU) precipitate was then filtered and the solution was concentrated in vacuo. After resuspending the crude product in $8 \mathrm{~mL}$ of $\mathrm{CH}_{3} \mathrm{CN}$, the remaining DCU was precipitated and removed by filtration. The solvent was then evaporated under reduced pressure to give methylthio- $\mathrm{d}_{6}$-butyric hydroxysuccinimide ester $\mathbf{2}$ as a yellow solid in quantitative yield. ${ }^{1} \mathrm{H}$ NMR (500 MHz, $\mathrm{CDCl}_{3}$ ): $\delta 2.07$ (s, 3H), 2.82 (s, $4 \mathrm{H})$. Finally, a mixture of $2(2.23 \mathrm{~g}, 9.4 \mathrm{mmol})$ and iodomethane $(1.76 \mathrm{~mL}, 28.2 \mathrm{mmol})$ in $\mathrm{CH}_{3} \mathrm{CN}(16 \mathrm{~mL})$ was allowed to react at room temperature in the dark for $2 \mathrm{~d}$. After solvent evaporation under reduced pressure, the resultant yellow solid was washed with dichloromethane and dried in vacuo to give pale-yellow crystals of $\mathrm{D}_{6}$-light DMBNHS (Supplementary Scheme S1) in $86 \%$ yield $(3.06 \mathrm{~g})$. The compound was stored in the dark prior to future use. ${ }^{1} \mathrm{H}$ NMR $\left(500 \mathrm{MHz}, \mathrm{CD}_{3} \mathrm{CN}\right): \delta 2.77(\mathrm{~s}, 4 \mathrm{H})$, $2.83(\mathrm{~s}, 6 \mathrm{H})$.

\section{$S, S^{\prime}-d_{6}$-Dimethylthiobutanoylhydroxysuccinimide Ester Iodide (D ${ }^{-H e a v y ~ D M B N H S)}$}

Based on the method of Jessing [62], 4-bromobutyric acid $(8.35 \mathrm{~g}, 50.0 \mathrm{mmol})$ and thiourea $(5.70 \mathrm{~g}, 75.0 \mathrm{mmol})$ were dissolved in $100 \mathrm{~mL}$ of ethanol and refluxed overnight. The solvent was then evaporated under reduced pressure and $65 \mathrm{~mL}$ of $7.5 \mathrm{M} \mathrm{NaOH}$ (aq) was added. The mixture was refluxed at $90{ }^{\circ} \mathrm{C}$ under a $\mathrm{N}_{2}$ atmosphere. After a $16 \mathrm{~h}$ reaction, $2 \mathrm{M} \mathrm{H}_{2} \mathrm{SO}_{4}$ was added slowly while stirring in an ice bath until the $\mathrm{pH}=1$. The resulting mixture was extracted 4 times with $60 \mathrm{~mL}$ of $\mathrm{CH}_{2} \mathrm{Cl}_{2}$, dried over anhydrous $\mathrm{MgSO}_{4}$, and concentrated in vacuo to give $5.27 \mathrm{~g}(88 \%)$ of thiobutyric acid $\mathbf{3}$ as a colorless oil. ${ }^{1} \mathrm{H}$ NMR $(500 \mathrm{MHz}$, $\mathrm{CDCl}_{3}$ ): $\delta 1.33$ (t, $1 \mathrm{H}, J=8.0 \mathrm{~Hz}$ ), 1.93 (qui, $2 \mathrm{H}, J=7.0 \mathrm{~Hz}$ ), $2.50(\mathrm{t}, 2 \mathrm{H}, J=7.0 \mathrm{~Hz}), 2.59$ (q, 2H, $J=7.0 \mathrm{~Hz}), 11.28(\mathrm{~s}$, 
broad, $1 \mathrm{H})$. Then, using a procedure adapted from Crouch et al. [63], potassium hydroxide $(1.31 \mathrm{~g}, 23.4 \mathrm{mmol})$ in $2 \mathrm{~mL}$ of methanol was added dropwise to $3(1.08 \mathrm{~g}, 9 \mathrm{mmol})$ dissolved in $10 \mathrm{~mL}$ of methanol in an ice bath and stirred for $10 \mathrm{~min}$. Iodomethane- $\mathrm{d}_{3}(672.4 \mu \mathrm{L}, 10.8 \mathrm{mmol})$ was added slowly over $10 \mathrm{~min}$ and the solution was stirred at room temperature overnight. After evaporating the solvent under reduced pressure, $12 \mathrm{~mL}$ of $\mathrm{H}_{2} \mathrm{O}$ was added followed by $2 \mathrm{M} \mathrm{HCl}$ until the $\mathrm{pH}=1$. The solution was extracted with $4 \times 18 \mathrm{~mL}$ of diethyl ether. The organic extracts were combined and dried over anhydrous $\mathrm{MgSO}_{4}$. The solvent was removed in vacuo and $858.2 \mathrm{mg}(70 \%)$ of $\mathrm{d}_{3}-$ methylmercaptobutyric acid $\mathbf{4}$ was obtained as brown oil. ${ }^{1} \mathrm{H}$ NMR (500 MHz, $\mathrm{CDCl}_{3}$ ): $\delta 1.92$ (qui, $2 \mathrm{H}, J=7.0 \mathrm{~Hz}$ ), 2.48 (t, $2 \mathrm{H}, J=7.5 \mathrm{~Hz}$ ), 2.53 (t, $2 \mathrm{H}, J=7.5 \mathrm{~Hz}$ ), 11.19 (s, broad, $1 \mathrm{H})$. Then, under a $\mathrm{N}_{2}$ atmosphere, NHS (792.4 mg, $6.89 \mathrm{mmol})$ and $4(858.2 \mathrm{mg}, 6.26 \mathrm{mmol})$ were dissolved in a mixture of $\mathrm{CHCl}_{3}(15 \mathrm{~mL})$ and $\mathrm{CH}_{2} \mathrm{Cl}_{2}(10 \mathrm{~mL})$. The mixture was stirred for 5 minutes at room temperature, then DCC (1419.5 mg, $6.89 \mathrm{mmol})$ was added and a precipitate formed immediately. The resulting slurry was stirred in a $\mathrm{N}_{2}$ atmosphere. After $18 \mathrm{~h}$, the mixture was filtered; the filtrate was collected and concentrated under reduced pressure. Then $\mathrm{CH}_{3} \mathrm{CN}(3 \mathrm{~mL})$ was added and the precipitate was filtered out. The solvent was removed in vacuo to yield $d_{3^{-}}$methylmercaptobutyric hydroxysuccinimide ester $\mathbf{5}$ as a yellow solid with a quantitative yield. ${ }^{1} \mathrm{H}$ NMR $(500 \mathrm{MHz}$, $\mathrm{CDCl}_{3}$ ): $\delta 2.02$ (qui, $2 \mathrm{H}, J=7.5 \mathrm{~Hz}$ ), $2.58(\mathrm{t}, 2 \mathrm{H}, J=7.5 \mathrm{~Hz}$ ), $2.74(\mathrm{t}, 2 \mathrm{H}, J=7.0 \mathrm{~Hz}), 2.82$ (s, 4H). Finally, 5 (933.6 mg, $3.99 \mathrm{mmol})$ and $\mathrm{d}_{3}$-iodomethane $(1.16 \mathrm{~g}, 7.98 \mathrm{mmol})$ were dissolved in $\mathrm{CH}_{3} \mathrm{CN}(8 \mathrm{~mL})$ and stirred in the dark at room temperature for $2 \mathrm{~d}$. The resulting solution was concentrated under reduced pressure. The resultant yellow solid was washed with dichloromethane and then dried in vacuo over night to yield $1.19 \mathrm{~g}(79 \%)$ of $\mathrm{D}_{6}$-heavy DMBNHS (Supplementary Scheme S2) as a white solid. The product was stored in the dark until further use. ${ }^{1} \mathrm{H}$ NMR $(500 \mathrm{MHz}$, $\mathrm{CD}_{3} \mathrm{CN}$ ): $\delta 2.16$ (qui, $2 \mathrm{H}, J=7.5 \mathrm{~Hz}$ ), 2.77 (s, $\left.4 \mathrm{H}\right), 2.85$ (t, $2 \mathrm{H}, J=7.5 \mathrm{~Hz}), 3.30(\mathrm{~m}, 2 \mathrm{H})$.

\section{Derivatization and Sample Preparation}

Phosphopeptides (see Supplementary Table S1) were dissolved in phosphate-buffered saline $(800 \mathrm{mg}$ of $\mathrm{NaCl}$, $217 \mathrm{mg}$ of $\mathrm{Na}_{2} \mathrm{HPO}_{4} \cdot 7 \mathrm{H}_{2} \mathrm{O}, 20 \mathrm{mg}$ of $\mathrm{KCl}$, and $20 \mathrm{mg}$ of $\mathrm{KH}_{2} \mathrm{PO}_{4}$ per $100 \mathrm{~mL}, \mathrm{pH} 7.5$ ) to a concentration of $10 \mu \mathrm{M}$ of each peptide. DMBNHS was dissolved in DMF and added to the phosphopeptide solution at a 200 to 400 -molar excess of reagent to primary amine [the final DMF volume was $10 \%(\mathrm{vol} / \mathrm{vol})]$. The reaction was allowed to proceed for $30 \mathrm{~min}$ at room temperature in the dark then was quenched by the addition of a 160-molar excess of Tris $(0.5 \mathrm{M}$, $\mathrm{pH} 8.26$ at $25{ }^{\circ} \mathrm{C}$ ) with incubation at room temperature for $10 \mathrm{~min}$ to ensure complete deactivation of the derivatization reagent. In order to compare the ionization efficiencies of underivatized and DMBNHS derivatized phosphopeptides, equal amounts of underivatized phosphopeptides were then spiked into the solutions, which was diluted to a final individual peptide concentration of $0.2 \mu \mathrm{M}$ with $3 \%$ acetic acid $/ 5 \% \mathrm{CH}_{3} \mathrm{CN}$ prior to HPLC-MS analysis.

For a proof-of-principle demonstration of quantitative analysis, the same reaction conditions were employed for isobaric differential isotope labeling of a 6-phosphopeptide mixture (no.. 3, 7, 22, 24, 27, and 44 in Table S1), using either $\mathrm{D}_{6}$-light DMBNHS or $\mathrm{D}_{6}$-heavy DMBNHS reagent. $40 \mu \mathrm{L}$ of peptide solution ( $25 \mu \mathrm{M}$ each peptide) was combined with $4 \mu \mathrm{L}$ of reagent solution $(0.4 \mathrm{M}$ in DMF) to maintain a 200 -molar excess of reagent to primary amine group. Following incubation and quenching, the $\mathrm{D}_{6}$-light and $\mathrm{D}_{6}$-heavy DMBNHS labeled phosphopeptide mixtures were pooled in molar ratios of 5:1, 2:1, 1:1, 1:2, and 1:5. Each solution was then diluted into $3 \%$ acetic acid $/ 5 \%$ $\mathrm{CH}_{3} \mathrm{CN}$ prior to HPLC-MS analysis.

\section{HPLC-ESI-MS, CID-MS/MS, $-M S^{3}$, and ETD-MS/ $M S$}

HPLC-MS, -MS/MS, and -MS ${ }^{3}$ analysis was performed using either an LTQ or LTQ XL linear quadrupole ion trap mass spectrometer (Thermo Fisher Scientific, San Jose, CA, USA) coupled with a Paradigm MS4 capillary RP-HPLC system (Michrom Bioresources, Auburn, CA, USA) equipped with an Advance nESI source. Phosphopeptide mixtures were separated on a $200 \mu \mathrm{m}$ i.d. $\times 50 \mathrm{~mm}$ fused silica column packed with Magic C18 (3 $\mu \mathrm{m}, 200 \AA$; Michrom Bioresources). Gradient elution was performed linearly over a 45 -min period from $95 \%$ solvent $\mathrm{A}(0.1 \%$ formic acid in $\left.\mathrm{H}_{2} \mathrm{O}\right)$ to $50 \%$ solvent $\mathrm{B}\left(0.1 \%\right.$ formic acid in $\left.\mathrm{CH}_{3} \mathrm{CN}\right)$ at a flow rate of $2 \mu \mathrm{L} \mathrm{min}{ }^{-1}$. The ion transfer tube of the mass spectrometer was set at $180{ }^{\circ} \mathrm{C}$ and the spray voltage was maintained at $2.0 \mathrm{kV}$. All MS and MS/MS spectra were collected automatically using methods created with the Xcalibur software (Thermo, San Jose, CA, USA) and all spectra were recorded in centroid mode. For CID-MS/MS and $-\mathrm{MS}^{3}$ analysis using the LTQ, the top three most abundant precursor ions from each MS scan above a threshold of 10,000 counts were selected for CID-MS/MS using standard conditions. The isolation window was maintained at $2.0 \mathrm{~m} / \mathrm{z}$ and the normalized collision energy was set at $25 \%$. Then, automated CID-MS ${ }^{3}$ was performed using a data-dependent constant neutral loss scan mode (DDCNL) of operation, as previously described [60]. When target neutral losses (see Supplementary Tables S2 and S3) within an $\mathrm{m} / \mathrm{z}$ variance of \pm 0.5 were detected above a threshold of $10,000, \mathrm{CID} \mathrm{MS}^{3}$ was automatically initiated to further fragment the most abundant neutral loss product ion. Dynamic exclusion was enabled to allow a maximum of five analyses of the selected $\mathrm{m} / \mathrm{z}$ within $30 \mathrm{~s}$ before it was placed on a dynamic exclusion list for a period of $10 \mathrm{~s}$. Alternatively, using the LTQ XL operated in an ' $\mathrm{N}^{\text {th }}$ order double play with ETD' mode of operation, the top five precursor ions from each MS scan above a threshold abundance of 
10,000 counts were selected for sequential CID-MS/MS and ETD-MS/MS analysis, with the isolation window maintained at $2.0 \mathrm{~m} / \mathrm{z}$. The normalized collision energy was set at $30 \%$ for CID experiments. ETD experiments were carried out by using fluoranthene anions as the electron-transfer reagent with optimized reaction times of $30 \mathrm{~ms}$ and $\mathrm{ETcaD}$ enabled.

\section{Data Analysis}

The relative abundance of phosphopeptide ions was determined from the full mass spectra averaged over the corresponding chromatographic peaks. The total ionization efficiency was calculated as the sum of the relative abundances of each observed peptide ion charge state. Quantitative analysis was achieved by calculating the ratio of "light" and "heavy" labeled neutral loss [i.e., $\mathrm{S}\left(\mathrm{CH}_{3}\right)_{2}$ and $\mathrm{S}\left(\mathrm{CD}_{3}\right)_{2}$ ] product ion abundances determined following HPLC-CID-MS/MS analysis of $\mathrm{D}_{6}$-light and $\mathrm{D}_{6}$-heavy DMBNHS labeled phosphopeptides for all available charge states. Multiple neutral losses were observed from multiply modified phosphopeptides. In some cases, other neutral losses such as $\mathrm{H}_{2} \mathrm{O}$ and $\mathrm{NH}_{3}$ were also observed along with the target neutral losses. In these cases, the summed abundances from all neutral loss product ions were used for determination of the ratio. During ETD-MS/MS, neutral losses of $\mathrm{S}\left(\mathrm{CH}_{3}\right)_{2}$ or $\mathrm{S}\left(\mathrm{CD}_{3}\right)_{2}$ were observed from the intact charge reduced precursor ions. In these cases, the same calculations as those described above were applied for relative quantitative analysis.

\section{Results and Discussion}

\section{Evaluation of ESI-MS Ionization Efficiencies and Charge State Distributions of Phosphopeptide Ions upon DMBNHS Derivatization}

To determine the effect of DMBNHS derivatization on ESIMS ionization efficiencies and charge state distributions compared to their non-derivatized forms, 50 'tryptic' phosphopeptides whose sequences, phosphorylation site locations, number of phosphorylation sites, peptide mass, peptide charge states, potential for missed cleavages etc.; are representative of in vivo phosphopeptides previously reported in the literature were synthesized, subjected to reaction with DMBNHS, mixed with an equal amount of unmodified peptide, then analyzed by HPLC-ESI-MS. To avoid signal suppression among co-eluting phosphopeptides, the 50 peptides were divided into 10 groups prior to analysis. Some peptides were present in multiple mixtures in order to evaluate inter-sample variances. The normalized and absolute abundances of each phosphopeptide are shown in Figure 1 and in the inset to Figure 1, respectively, in an order corresponding to the observed chromatographic elution times of the underivatized peptides. Triplicate analysis was found to result in less than $20 \%$ variation in abundance for each phosphopeptide.

An average 2.5-fold increase in total ESI-MS ionization efficiency was observed for the derivatized peptides compared with their non-derivatized forms. Interestingly, an average 1.8-fold enhancement was observed for singly modified phosphopeptides (i.e., those containing only a single amino group at the N-terminus), while an average 3.5fold enhancement was observed for doubly modified species

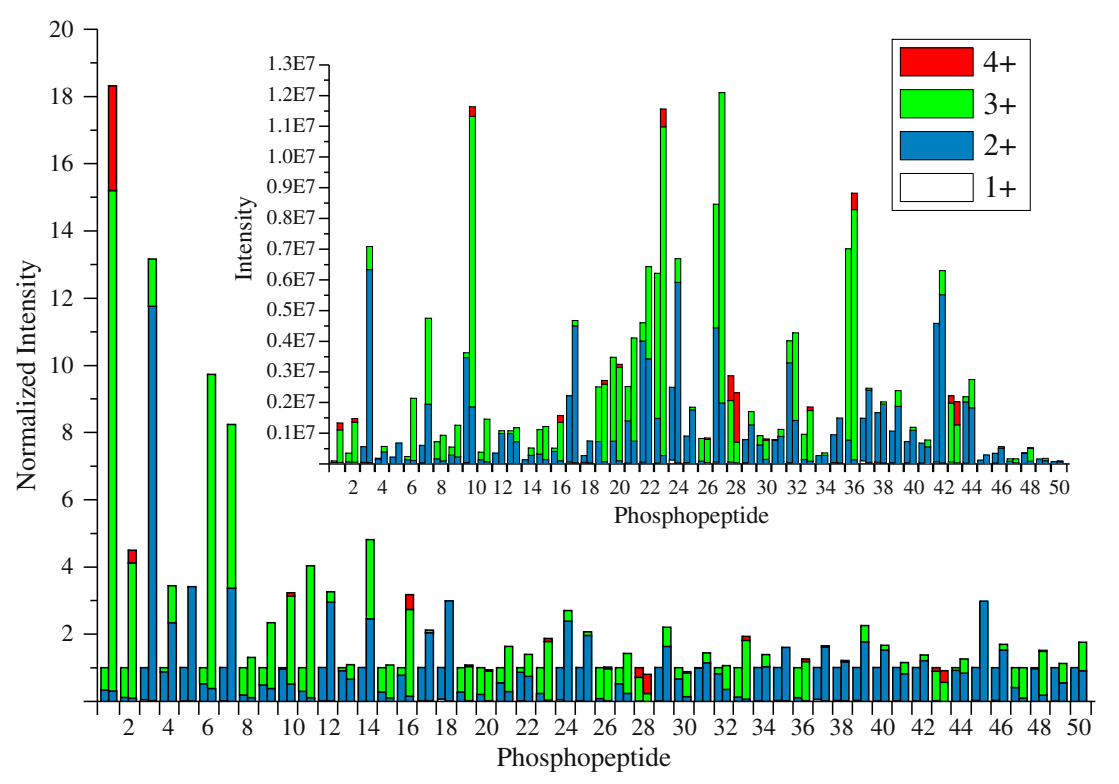

Figure 1. Normalized intensities and charge state distributions of 50 underivatized and DMBNHS derivatized phosphopeptides following HPLC-MS analysis. The sequence of each phosphopeptide is listed in Table S1. For each peptide, the underivatized and derivatized peptide data are shown on the left and right hand side of each column, respectively. The inset shows the measured intensities for each peptide 
(i.e., those containing $\mathrm{N}$-terminal amino and lysine side chain $\varepsilon$-amino groups), indicating an accumulation effect from the presence of multiple fixed charge derivatives. It was observed that DMBNHS labeled phosphopeptides generally had longer retention times than their unlabeled counterparts, likely due to the increased hydrophobicity of the alkyl chain that was present within the DMBNHS label (s). It was also observed that earlier-eluting phosphopeptides generally demonstrated a greater enhancement in ionization efficiency compared to later-eluting ones, suggesting that the magnitude of enhancement in ionization efficiency upon DMBNHS labeling was related to the phosphopeptide's hydrophobicity [64]. For example, for phosphopeptides 1 (ETEEQDpSDSAEQGDPAGEGK) and 50 (AFLpSPPTLLEGPLR), which eluted first and last from the reversed-phase C18 column among the 50 peptides examined here, the doubly modified peptide 1 experienced an 18.3-fold increase in total ionization efficiency (with a significant difference in elution time between the modified and unmodified peptide of $+6.06 \mathrm{~min}$ ); while there was only a 1.76 -fold increase for the singly modified peptide 50 (with an essentially unchanged difference in elution time between the modified and unmodified peptide of $-0.36 \mathrm{~min}$ ). Typically, there is a linear relationship between peptide retention time in RP-HPLC and its hydrophobicity index [65]; hence, it may be concluded that the more hydrophilic phosphopeptides tend to be more effective for improved ionization efficiency by fixed charge DMBNHS labeling, and that the contribution of DMBNHS derivatization to improved phosphopeptide ionization efficiency and charge state distribution is not simply due to the presence of the positively charged sulfonium ion, but also from the presence of the hydrophobic propyl chain within the tag attached to the modified amino group. In addition, due to their typical longer retention times, labeled phosphopeptides are eluted into the mass spectrometer with a higher fraction of organic solvent compared to their unlabeled forms, which may also facilitate improved ESI efficiencies [66].

In addition to an increase in overall ionization efficiencies, another important outcome of DMBNHS derivatization was an increase in precursor ion charge states and/or abundances (see Table S1 for the observed abundances and $\%$ charge state abundances of each unlabeled and labeled phosphopeptide). A summary of the average $\%$ charge state intensities following HPLC-ESI/MS of the 50 underivatized and DMBNHS derivatized phosphopeptides is shown in Table 1, along with separate summaries for the singly and doubly modified phosphopeptides. Twenty-two of the 50 phosphopeptides (44\%) yielded precursor ions with maximum charge states corresponding to +2 in their underivatized states, 26 had precursor ions with maximum charge states corresponding to +3 , and two had precursor ions with maximum charge states corresponding to +4 . In contrast, following DMBNHS derivatization, only 4 of the 50 phosphopeptides yielded precursor ions whose maximum charge states were still +2 , while 33 had precursor ions with maximum charge states corresponding to +3 , and 13 had precursor ions with maximum charge states corresponding to +4 . Overall, higher charge states were observed for 29 of the 50 labeled phosphopeptides following derivatization. For example, for phosphopeptide no. 39 (pSPGAPGPLTLK) that gave an overall 2.25-fold increase in ionization efficiency upon labeling, only singly and doubly charged precursor ions were observed before derivatization (Figure 2a) while the doubly DMBNHS modified form of the peptide (Figure 2b) yielded abundant doubly and triply charged species. Similarly, phosphopeptide no. 23 (VGEEEHVpYSFPNK) gave an overall 1.87 -fold increase in ionization, with an increase from doubly and triply charged precursor ions in the underivatized state, to doubly, triply, and quadruply charged precursor ion species upon derivatization (see Supplementary Figure S1A and B, respectively). The data in Table 1 indicates that doubly-modified peptides gave rise to a greater increase in maximum charge states upon derivatization, which is consistent with the results described above regarding the overall increases in ionization efficiency for doubly versus singly DMBNHS modified phosphopeptides.

Importantly, for the 21 phosphopeptides whose maximum charge states were not observed to increase upon labeling, an increase in the abundance of the highest charge state present

Table 1. Average \% Charge State Intensities Following HPLC-ESI/MS of Underivatized and DMBNHS Derivatized Phosphopeptides

All phosphopeptides (50)

Unlabeled

Labeled

Ratio (labeled/unlabeled)

Phosphopeptides containing 1 modifiable site (30)

Unlabeled

Labeled

Ratio (labeled/unlabeled)

Phosphopeptides containing 2 modifiable sites (20)

Unlabeled

Labeled

Ratio (labeled/unlabeled)

\footnotetext{
${ }^{\text {a }}$ Errors indicate \pm standard deviation

Errors indicate \pm standard deviation
}

\begin{tabular}{lcl}
\multicolumn{2}{c}{ Average \% charge state intensities } & \\
$2+$ & $3+$ & $4+$ \\
$70.13 \pm 35.27$ & $28.24 \pm 34.58$ & $0.79 \pm 4.29$ \\
$46.33 \pm 38.67$ & $49.87 \pm 35.94$ & $3.75 \pm 11.45$ \\
0.66 & 1.77 & 4.75
\end{tabular}

$1+$

$1.03 \pm 1.57$

$0.09 \pm 0.15$

0.087

$1+$

$0.57 \pm 1.04$

$0.00 \pm 0.01$

0.00
$4+$

$1.31 \pm 5.51$

$3.99 \pm 14.34$ 3.05 


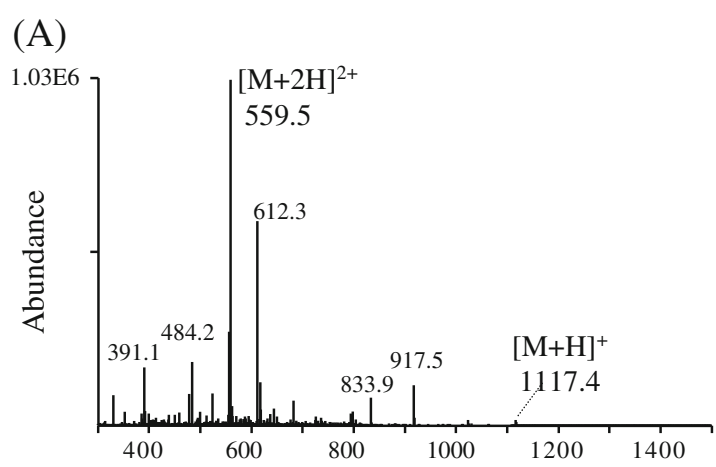

(B)

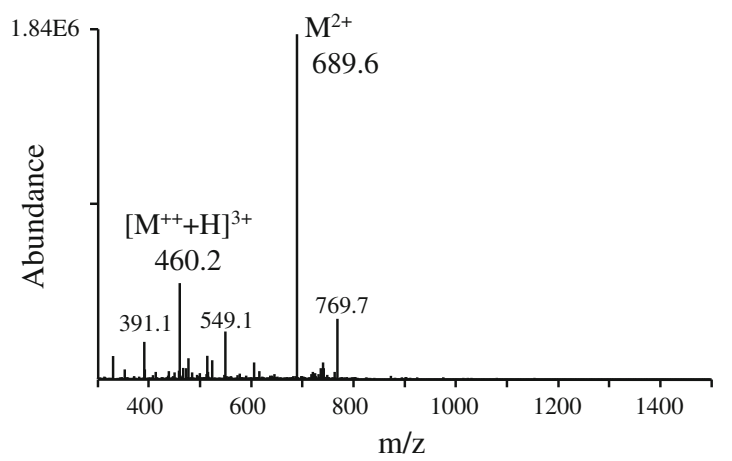

(C)

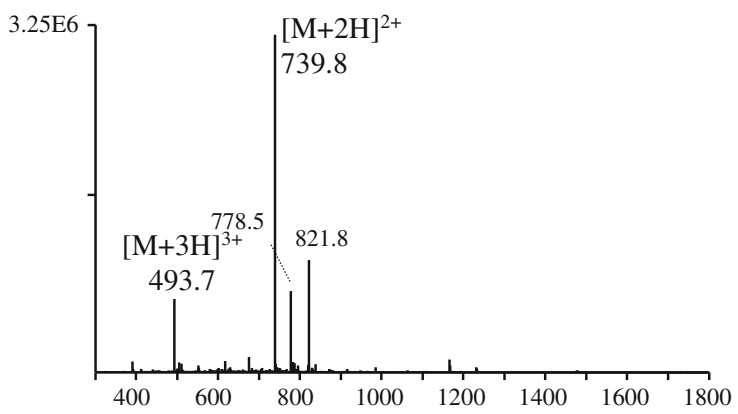

(D)

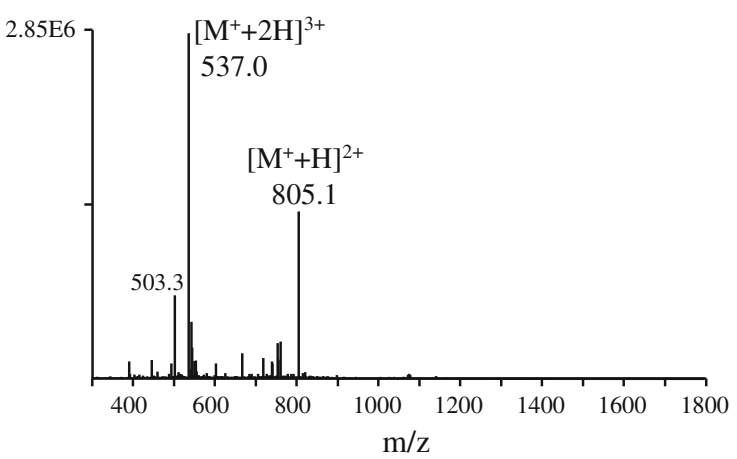

Figure 2. HPLC-ESI-MS spectra of underivatized and DMBNHS derivatized phosphopeptide no. 39 (pSPGAPGPLTLK) [panels (A) and (B), respectively] and phosphopeptide no. 32 (pYATPQVIQAPGPR) [panels (C) and (D), respectively]

was observed in each case. For example, Figure $2 \mathrm{c}$ and $\mathrm{d}$ show the spectra obtained following HPLC-ESI-MS analysis of the unmodified and singly DMBNHS modified phosphopeptide no. 32 (pYATPQVIQAPGPR). For this peptide, although only a very modest 1.06 -fold increase in overall ionization efficiency was observed, a 3.98-fold increase in the abundance of the triply charged precursor (i.e., the highest observed charge state) from $7.15 \mathrm{E}^{5}$ to $2.85 \mathrm{E}^{6}$ was still achieved. Similarly, for phosphopeptide no. 43 (LGHPEALSAGpTGSPQPPSFTYAQQR), (see Supplementary Figure S1C and D, respectively) the abundance of the highest observed quadruply charged precursor ion charge state was increased from $2.50 \mathrm{E}^{5}$ to $7.38 \mathrm{E}^{5}$ (2.95-fold), despite a minor decrease in overall ionization efficiency (0.91-fold) upon derivatization.

\section{Fixed Charge Sulfonium Ion Derivatization} for Enhanced Collision Induced Dissociation (CID) and Electron Transfer Dissociation (ETD) Characterization of Phosphopeptide Ions

\section{CID-MS/MS and $-M S^{3}$ Analysis of DMBNHS Labeled Phosphopeptides}

CID-MS/MS and $-\mathrm{MS}^{3}$ spectra of the singly DMBNHS modified phosphopeptide no. 43 (LGHPEALSAGpTGSPQPPSFTYAQQR) are shown in Figure $3 \mathrm{a}$ and $\mathrm{b}$, respectively. Consistent with previous studies on the gas-phase fragmentation reactions of fixed charge sulfonium ion containing peptides, the exclusive neutral loss of dimethylsulfide [S $\left(\mathrm{CH}_{3}\right)_{2}$ ] was observed upon dissociation of the triply charged $\left[\mathrm{M}^{+}+2 \mathrm{H}\right]^{3+}$ precursor ion [56-61]. Notably, also consistent with previous results, the lability of the sulfonium ion derivative to undergo cleavage resulting in the specific neutral loss of $\mathrm{S}\left(\mathrm{CH}_{3}\right)_{2}$ was found to essentially completely suppress any competing loss of $\mathrm{H}_{3} \mathrm{PO}_{4}$ from the phosphothreonine side chain [61]. CID$\mathrm{MS}^{3}$ of the neutral loss product ion from Figure 3a (see Figure $3 b$ ) gave rise to a range of sequence-type product ions resulting from cleavages along the peptide backbone, from which the peptide sequence and site of phosphorylation could potentially be derived, together with some relatively low abundance non-sequence-type ions corresponding to losses of the phosphate group and/or water from the precursor or sequence-type product ions. It is expected that as the proton affinity of the product ion structure formed via the loss of dimethylsulfide during CID-MS/MS (previously proposed to be a cyclic iminohydrofuran (IHF) moiety $[58,60]$ ) will be higher than that of an amino group [60], the neutral loss product ion that is initially formed may have decreased proton mobility compared to that of the unmodified peptide of the same charge state. Decreased proton mobility within IHFmodified phosphopeptides could lead to more abundant loss of the phosphate group or increase the potential for phosphate 

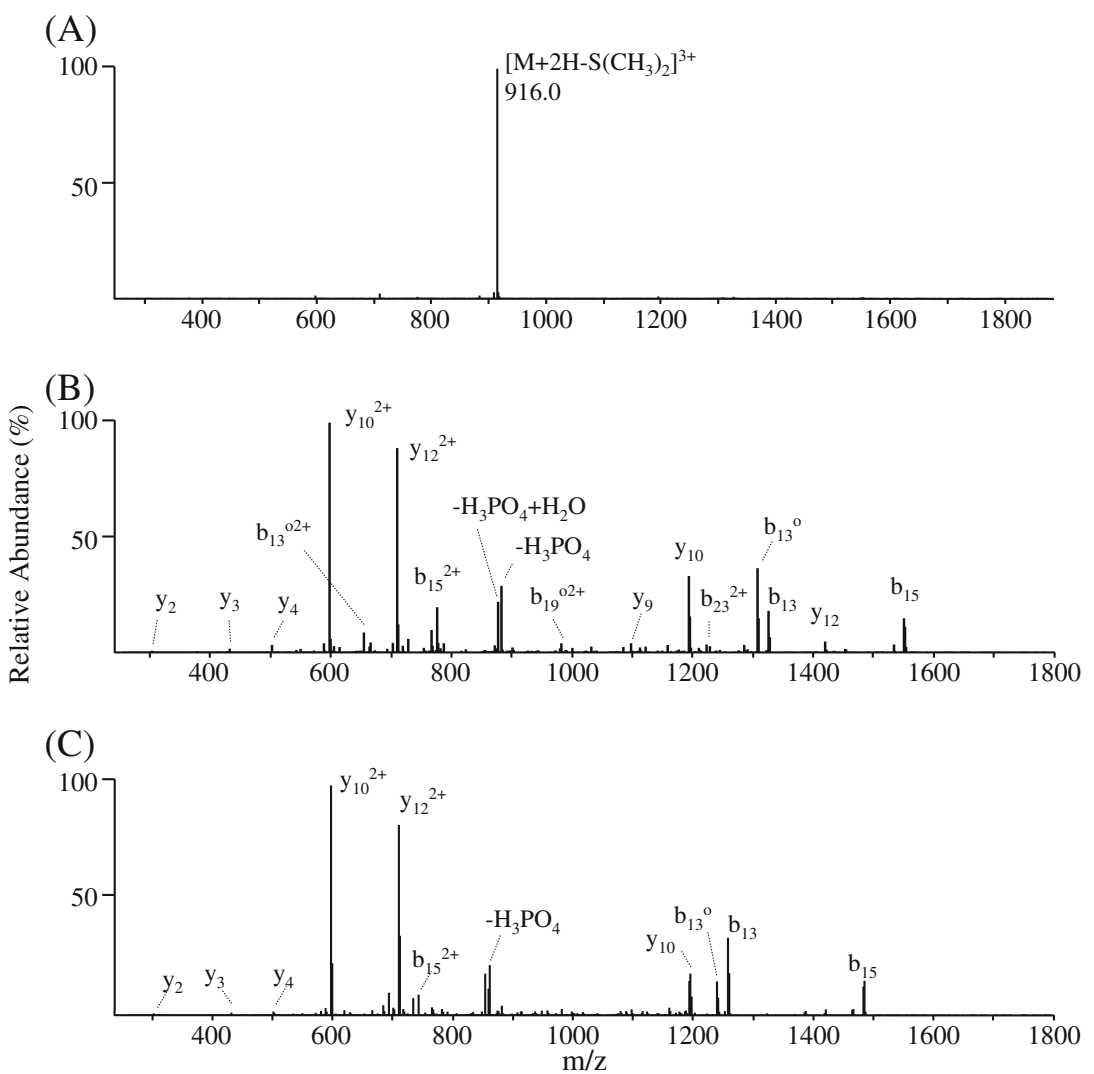

Figure 3. ESI-MS ${ }^{n}$ analysis of phosphopeptide no. 43 (LGHPEALSAGpTGSPQPPSFTYAQQR). (A) CID-MS/MS of the [M+ ${ }^{+}+$ $2 \mathrm{H}]^{3+}$ precursor ion from the singly derivatized phosphopeptide. (B) CID-MS ${ }^{3}$ of the $\mathrm{m} / \mathrm{z} 916.0$ neutral loss product ion from panel (B). (C) CID-MS/MS of the $[\mathrm{M}+3 \mathrm{H}]^{3+}$ precursor ion from the underivatized phosphopeptide. $\Delta=-98 \mathrm{Da}\left(-\mathrm{H}_{3} \mathrm{PO}_{4}\right.$ or $\left.\left(\mathrm{HPO}_{3}+\mathrm{H}_{2} \mathrm{O}\right)\right) ; \mathrm{o}=-18 \mathrm{Da}\left(\mathrm{H}_{2} \mathrm{O}\right)$

group 'scrambling' under CID-MS ${ }^{3}$ conditions [12], which therefore could limit the extent of unambiguous sequence information for subsequent phosphopeptide identification and characterization. However, for the DMBNHS derivatized phosphopeptide no. 43, the appearance of the CID-MS ${ }^{3}$ spectrum was very similar to that obtained by CID-MS/MS of the unmodified triply protonated $\left([\mathrm{M}+3 \mathrm{H}]^{3+}\right)$ precursor ion shown in Figure $3 \mathrm{c}$, demonstrating that in this case, the initial product ion is stable to further dissociation involving the IHF-moiety, and had only a limited influence on CID-MS ${ }^{3}$ product ion formation compared to the unmodified peptide.

CID-MS/MS of the doubly modified phosphotyrosinecontaining peptide no. 23 (VGEEEHVpYSFPNK) yielded two product ions corresponding to the characteristic sequential exclusive neutral losses of one and two $\mathrm{S}\left(\mathrm{CH}_{3}\right)_{2}$ molecules, thereby providing diagnostic information regarding the presence of a lysine residue within the peptide, in addition to the $\alpha$ amino group (Figure 4a). Similar characteristic double neutral losses were observed for all peptides that were doubly DMBNHS modified (another example is shown in Supplementary Figure S2A for the doubly modified phosphoserinecontaining peptide no. 46 (ASpSLEDLVLK)). The presence of these diagnostic double neutral losses could easily be utilized for pre- or post-search filtering to improve the specificity of database search procedures for large scale protein sequence analysis, analogous to that previously described using the characteristic immonium ions formed by CID-MS/MS [67], or the diagnostic neutral loss product ions formed by ETD-MS/ MS [68]. CID of the $m / z 584.5$ product ion from Figure 4a resulted in an $\mathrm{MS}^{3}$ product ion spectrum (Figure $4 \mathrm{~b}$ ) containing an abundant series of both b- and y-type ions and substantially greater sequence coverage compared to that obtained by CIDMS/MS of the unmodified peptide, which was dominated by a single $\mathrm{y}_{12}{ }^{2+}$ product ion (Figure 4c). This is likely due to a change in either the relative location of the ionizing protons between the two precursor ions, that altered the propensity for cleavage of particular amide bonds, or more likely due to an increase in the relative basicity of the N-terminal peptide fragments resulting from the presence of the IHF-moiety at the former $\alpha$-amino group within the DMBNHS derivatized peptide. In contrast, for the doubly DMBNHS modified phosphopeptide no. $46, \mathrm{CID}^{-\mathrm{MS}^{3}}$ of the product ion formed via the initial double neutral loss of two $\mathrm{S}(\mathrm{CH} 3)_{2}$ groups (Supplementary Figure S2B) resulted in a spectrum with essentially the same sequence ion coverage compared to the unmodified peptide (Supplementary Figure S2C), but with substantially more highly abundant $\mathrm{H}_{3} \mathrm{PO}_{4}$ neutral loss and $\mathrm{H}_{3} \mathrm{PO}_{4}+\mathrm{H}_{2} \mathrm{O}$ neutral loss product ions. In this case, the dominant loss of $\mathrm{H}_{3} \mathrm{PO}_{4}$, likely formed due to an overall 

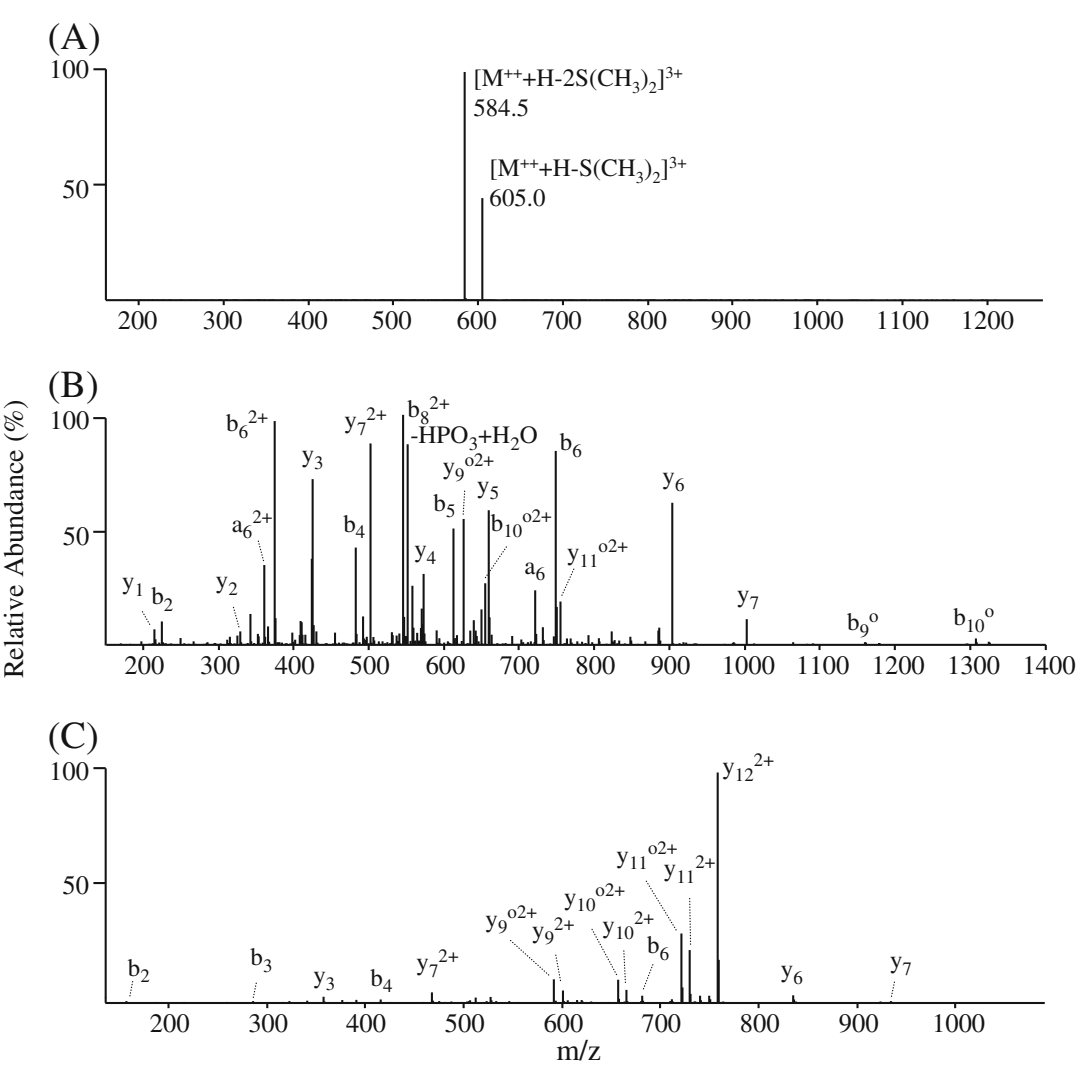

Figure 4. ESI-MS ${ }^{n}$ analysis of phosphopeptide no. 23 (VGEEEHVPYSFPNK). (A) CID-MS/MS of the $\left[M^{++}+H\right]^{3+}$ precursor ion from the doubly derivatized phosphopeptide. (B) CID-MS ${ }^{3}$ of the $\mathrm{m} / \mathrm{z} 584.5$ double neutral loss product ion from panel (A). (C) $\mathrm{CID}-\mathrm{MS} / \mathrm{MS}$ of the $[\mathrm{M}+3 \mathrm{H}]^{3+}$ precursor ion from the underivatized phosphopeptide. $\Delta=-98 \mathrm{Da}\left[-\mathrm{H}_{3} \mathrm{PO}_{4}\right.$ or $\left.-\left(\mathrm{HPO}_{3}+\mathrm{H}_{2} \mathrm{O}\right)\right] ; \mathrm{O}=$ $-18 \mathrm{Da}\left(\mathrm{H}_{2} \mathrm{O}\right)$

decrease in proton mobility or proton location within the initial neutral loss product ion formed by MS/MS, increases the possibility of phosphate group 'scrambling' [12]. Therefore, caution should be used in employing $\mathrm{CID}^{-\mathrm{MS}^{3}}$ as part of an analysis strategy coupled with DMBNHS labeling for the identification and characterization of unknown phosphopeptides.

\section{ETD-MS/MS Analysis of DMBNHS Labeled Phosphopeptides}

At present, the ETD fragmentation behavior of fixed charge sulfonium ion containing peptides has not been explored. Here, since ETD fragmentation efficiency is highly dependent on the charge density of the precursor ions, and typically a precursor ion charge state of at least $3+$ is required to obtain high quality ETD-MS/MS spectra (recall that a favorable shift from doubly to triply charged precursor ions was observed upon DMBNHS labeling; see Table 1), the ETD fragmentation behavior of triply charged phosphopeptide ions were of most interest to this study. A representative example of the ETD-MS/MS fragmentation for the triply charged precursor ions of a singly DMBNHS labeled and unlabeled phosphopeptide (peptide no. 43, LGHPEAL-
SAGpTGSPQPPSFTYAQQR) are shown in Figure 5a and $\mathrm{b}$, respectively, while Figure 6a and b show representative ETD-MS/MS spectra for a doubly DMBNHS labeled and unlabeled phosphopeptide (peptide no. 23, VGEEEHVpYSFPNK).

Notably, the fragmentation efficiency and z- and c-type product ion distributions and abundances observed following ETD of the triply charged singly DMBNHS labeled phosphopeptide 43 in Figure 5a were essentially identical to that of the unlabeled peptide in Figure 5b. A mass shift of $130 \mathrm{Da}$ observed on all c-type product ions confirmed that the modification was located at the amino group of the $\mathrm{N}$ terminus. The appearance of a low mass c-ion (e.g., $\left.c_{2}\right)$ in the product ion spectrum of the labeled peptide, which was not present in the spectrum of the unlabeled peptide, provided the potential to improve the overall sequence coverage for phosphopeptide characterization. Similarly increased numbers of low mass c-type ions in the ETD spectra of DMBNHS labeled peptides were observed for other phosphopeptides examined here (see below). The absence of the doubly charged $\mathrm{z}_{23}{ }^{2+}$ ion in the spectrum of the derivatized peptide is probably due to the reduced number of ionizing protons present within the labeled peptide (i.e., one of the three charge carriers is the fixed 


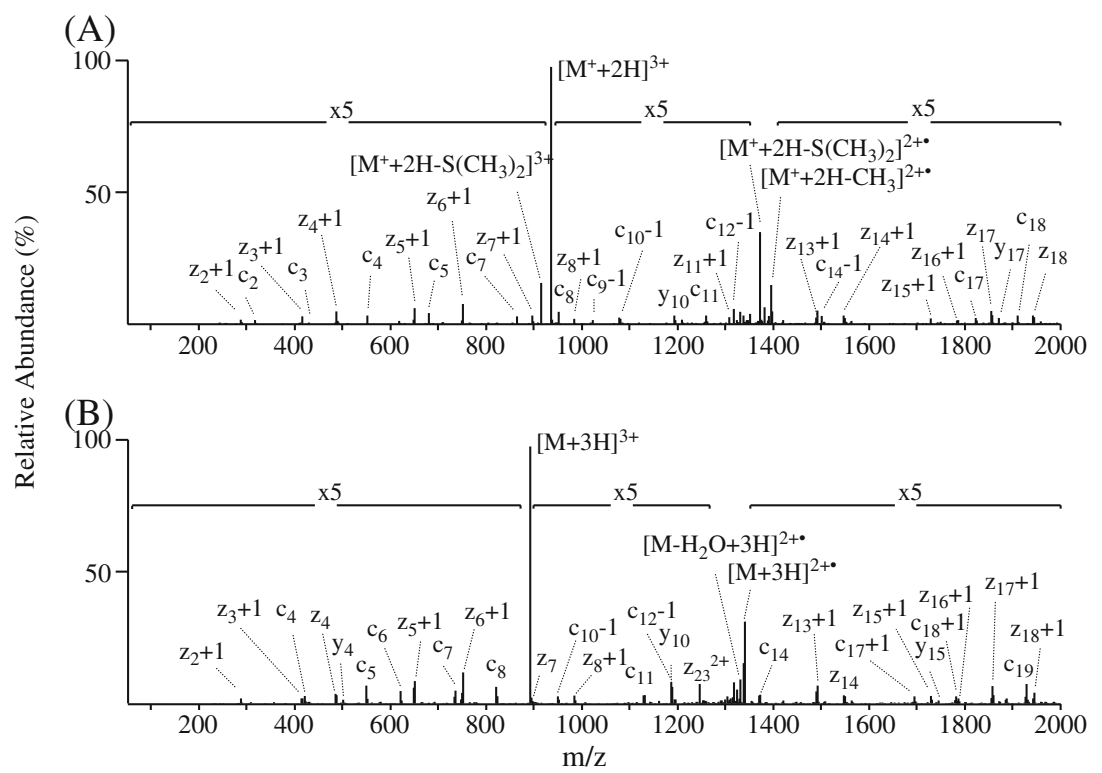

Figure 5. ETD-MS/MS analysis of phosphopeptide no. 43 (LGHPEALSAGPTGSPQPPSFTYAQQR). (A) ETD-MS/MS of the [M ${ }^{+}+$ $2 \mathrm{H}]^{3+}$ precursor ion from the singly derivatized phosphopeptide. (B) ETD-MS/MS of the $[\mathrm{M}+3 \mathrm{H}]^{3+}$ precursor ion from the underivatized phosphopeptide

charge sulfonium ion instead of a proton). Li et al. have previously reported a greatly reduced abundance of backbone fragments obtained via ECD-MS/MS of peptides labeled with 2,4,6-trimethylpyridine (TMP); the authors reasoned that the pyridinium ion can form a stable radical upon capture of the electron, such that further $\mathrm{N}-\mathrm{C} \alpha$ dissociations are suppressed [69]. However, enhanced sequence coverage has been reported following ECD of phosphonium labeled glycopeptides and phosphopeptides
[70], as well as following ETD of trimethylammonium labeled cysteine peptides [37]. This might be attributable to the different recombination energies of the introduced fixed charge containing functional groups compared to that of protonated basic groups within the peptides $[69,70]$.

Compared with the unlabeled phosphopeptide 43 (Figure $5 b$ ), the most significant difference observed in the ETD-MS/MS spectrum of the DMBNHS labeled peptide is the presence of abundant methyl radical and dimethylsulfide

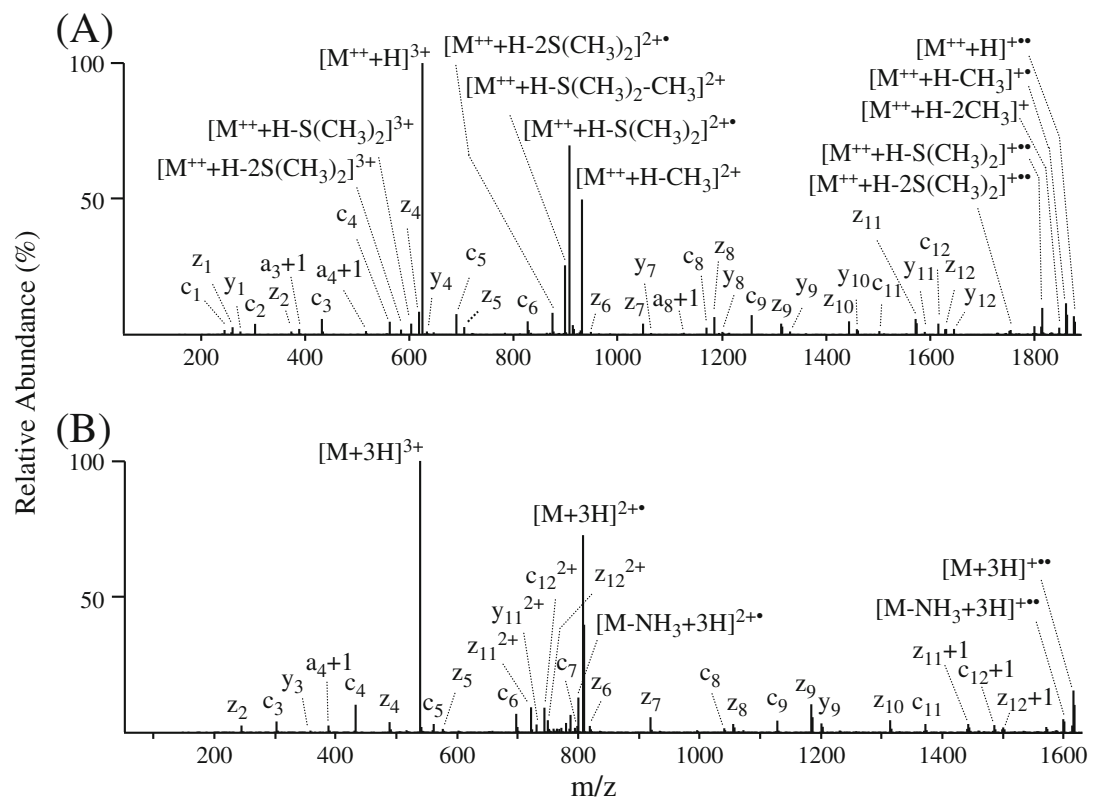

Figure 6. ETD-MS/MS analysis of phosphopeptide no. 23 (VGEEEHVPYSFPNK). (A) ETD-MS/MS of the $\left[\mathrm{M}^{++}+\mathrm{H}\right]^{3+}$ precursor ion from the doubly derivatized phosphopeptide. (B) ETD-MS/MS of the $[\mathrm{M}+3 \mathrm{H}]^{3+}$ precursor ion from the underivatized phosphopeptide 
neutral losses from the charge reduced intact doubly charged precursor ion (Figure 5a). Side-chain losses or entire losses of the tag have been a common observation from previous reports regarding dissociation of fixed charge derivatized peptides by electron driven techniques [37, 69, 70]. These fragmentations likely result from initial capture of the electron by the fixed charge functional group residing at either aromatic rings or aliphatic chains. Similarly, the transfer of an electron from the ETD anionic reagent to the fixed charge sulfonium ion derivative in the current study may result in formation of a sulfur radical (see Supplementary Scheme S3), which triggers subsequent homolytic cleavage of the adjacent $\mathrm{C}-\mathrm{S}$ bonds, and resulting in methyl radical or dimethylsulfide group losses. The presence of sequence ions resulting from peptide backbone $\mathrm{N}-\mathrm{C}_{\alpha}$ cleavage and from non-sequence ion side-chain losses resulting from cleavage at the sulfonium ion moiety indicates competition for the electron between the protonated peptide and the fixed charge tag. Interestingly, a low abundance dimethylsulfide neutral loss $(3.2 \%$ relative base peak abundance) was also observed from the intact precursor ion, similar to that observed from CID-MS/MS of DMBNHS labeled phosphopeptide. This loss is most likely generated by resonant collisional activation during precursor ion isolation, or by the supplemental collisional activation applied in the ETD experiments [71].

Similar results were also obtained when comparing the ETD-MS/MS spectra of the triply charged doubly labeled and unlabeled phosphotyrosine containing peptide VGEEEHVpYSFPNK (no. 23), as shown in Figure 6a and b, respectively. The addition of a second sulfonium ion containing tag did not cause any noticeable differences in the peptide backbone cleavage efficiency or product ion abundances. However, an overall increase in sequence coverage was achieved due to the appearance of low mass $c_{1}, c_{2}$, and $z_{1}$ ions. Similar to that discussed above, doubly charged product ions (e.g., $\mathrm{z}_{11}{ }^{2+}, \mathrm{y}_{11}{ }^{2}$ ${ }^{+}, \mathrm{c}_{12}{ }^{2+}$, and $\mathrm{z}_{12}{ }^{2+}$ ) observed as abundant products in the ETDMS/MS spectrum of the unlabeled peptide were not observed in the product ion spectrum for the doubly DMBNHS labeled peptide. Multiple neutral losses of abundant methyl radical and dimethylsulfide groups from the charge reduced intact precursor ions of the doubly DMBNHS labeled peptide were observed (Figure 6a). For the neutral loss products arising from the initial charge reduced doubly charged product, the loss of a second tag [i.e., $-\mathrm{S}\left(\mathrm{CH}_{3}\right)_{2}$ or $-\mathrm{CH}_{3} \bullet$ in addition to the loss of a first $\mathrm{S}\left(\mathrm{CH}_{3}\right)_{2}$ group] was probably a result of the applied supplemental collisional activation employed during ETD experiments, since only one electron was transferred to the peptide precursor ion. However, for the singly charged neutral loss product ions arising from the charge reduced singly charged intact precursor, secondary electron transfer likely induces cleavage on the second sulfonium ion tag. This is consistent with the fact that double $\mathrm{CH}_{3} \bullet$ losses were mainly found in the charge reduced singly charged intact precursor ions.

Another example is shown in Supplementary Figure S3A for ETD-MS/MS of the triply charged precursor ion of the doubly DMBNHS labeled phosphoserine containing peptide pSPGAPGPLTLK (no. 39). For the unmodified form of this peptide, ETD-MS/MS could only be obtained for the doubly protonated precursor ion, since a triply protonated precursor ion charge state was not observed in the MS spectrum (see Supplementary Figure S3B). Notably, only very limited and low abundance sequence ions were observed in the latter case, consistent with previous reports on the typically limited dissociation efficiency of low charge state precursor ions by ETD. Clearly, the formation of higher charge state precursor ions by using sulfonium ion derivatization enables enhanced dissociation efficiencies and increased sequence-coverage by using ETD, and allows access to a broader range of phosphopeptide sequences (up to $44 \%$ of the total) that may otherwise be inaccessible to analysis using this technique.

\section{Fixed Charge Sulfonium Ion Derivation Coupled with Isobaric Stable Isotope Labeling for Enhanced Collision Induced Dissociation (CID) and Electron Transfer Dissociation (ETD) Quantitative Phosphopeptide Analysis}

As described above, the introduction of sulfonium ion fixed charge derivatives to phosphopeptides provides improved ionization efficiencies and increased abundance high charge state precursor ions that are amenable to enhanced structural characterization and phosphorylation site localization by using ETD-MS/MS analysis strategies. Furthermore, the dissociation of sulfonium ion labeled phosphopeptides gave rise to exclusive $\mathrm{S}\left(\mathrm{CH}_{3}\right)_{2}$ neutral loss product ions upon CID-MS/MS. In order to apply this desirable ionization and gas-phase fragmentation behavior toward the sensitive differential quantitative analysis of phosphopeptide abundances, via ratiometric measurement of the relative abundances of the characteristic neutral loss product ions generated by CID-MS/MS dissociation of 'light' and 'heavy' labeled peptide ions, the novel isobaric stable isotope labeled sulfonium ion containing reagents $S, S^{\prime}$-dimethylthio-d $6^{-}$ butanoylhydroxysuccinimide ester iodide $\left(D_{6}\right.$-light DMBNHS) and $S, S^{\prime}$ - $\mathrm{d}_{6}$-dimethylthiobutanoylhydroxysuccinimide ester iodide ( $\mathrm{D}_{6}$-heavy DMBNHS) (Scheme 2$)$ were prepared by the introduction of six deuteriums into (1) the butyl chain of the DMBNHS structure, via the reaction of $\mathrm{d}_{6}-\gamma$-butyrolactone with sodium methanethiolate, followed by esterification with NHS and alkylation with iodomethane, or (2) the dimethylsulfide moiety of the DMBNHS structure, via the reaction of 4-bromobutyric acid with thiourea, followed by alkylation with $\mathrm{d}_{3}$-iodomethane, esterification with NHS and final alkylation with $\mathrm{d}_{3}$-iodomethane, respectively. Upon CID-MS/MS of a precursor ion containing the two isobaric peptides labeled with these two reagents, product ions corresponding to the exclusive neutral losses of $\mathrm{S}\left(\mathrm{CH}_{3}\right)_{2}(62 \mathrm{Da})$ and $\mathrm{S}\left(\mathrm{CD}_{3}\right)_{2}(68 \mathrm{Da})$ are expected (Scheme 2), which may be used for differential quantification of phosphopeptide abundances between two samples. Then, the same precursor ion can be automatically subjected 


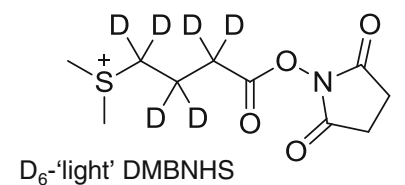<smiles>C[13CH][13CH]</smiles>

62 Da neutral loss

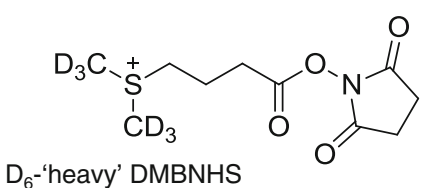

CID-MS/MS

68 Da neutral loss

Scheme 2. Structures and CID-MS/MS fragmentation reactions of the stable isotope labeled DMBNHS reagents $\mathrm{S}, \mathrm{S}^{\prime}$ dimethylthio- $\mathrm{d}_{6}$-butanoylhydroxysuccinimide ester iodide ( $\mathrm{D}_{6}$-light DMBNHS) and $\mathrm{S}, \mathrm{S}^{\prime}-\mathrm{d}_{6}$-dimethylthiobutanoylhydroxysuccinimide ester iodide $\left(\mathrm{D}_{6}\right.$-heavy DMBNHS)

to ETD-MS/MS to obtain the necessary structural information for phosphopeptide sequence identification and phosphorylation site localization.

In a proof of principle demonstration of this approach, a mixture of six synthetic phosphopeptides (no's. 3, 7, 22, 24, 27, and 44 in Table S1) were differentially labeled using either the $\mathrm{D}_{6}$-light or $\mathrm{D}_{6}$-heavy DMBNHS reagents, then pooled in a range of ratios from 5:1 to 1:5 and subjected to analysis by LCMS and data dependent CID- and ETD-MS/MS. Importantly, the $\mathrm{D}_{6}$-light and $\mathrm{D}_{6}$-heavy DMBNHS labeled phosphopeptides co-eluted from the reversed- phase C18 column, appearing as single chromatographic peaks for each peptide (Figure 7a). Due to their isobaric nature, differentially labeled peptides also appeared as single peaks in the MS spectra (an example is shown in Figure 7b for peptide no. 27), thereby providing an enhanced peak capacity for their detection. Following acquisition of each MS scan, precursor ions were then subjected to data dependent MS/MS analysis using an ' $\mathrm{N}^{\text {th }}$ order double play with ETD' mode of operation, whereby the top five precursor ions from each MS scan above a threshold

abundance of 10,000 counts were selected for sequential CID-MS/MS and ETD-MS/MS.

Representative spectra are shown in Figure $8 \mathrm{a}$ and $\mathrm{b}$ for dissociation of the triply charged singly labeled phosphoserine containing peptide LFTGHPEpSLER (no. 27), labeled with a 1:1 ratio of $\mathrm{D}_{6}$-light and $\mathrm{D}_{6}$-heavy DMBNHS reagent, using CID-MS/MS (Figure 8a) and ETD-MS/MS (Figure 8b). As expected, two product ions were exclusively formed upon CID-

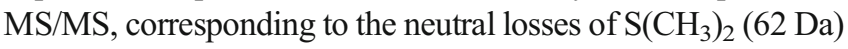
and $\mathrm{S}\left(\mathrm{CD}_{3}\right)_{2}(68 \mathrm{Da})$, respectively (inset to Figure $\left.8 \mathrm{a}\right)$. A similar result was also observed by CID-MS/MS of the doubly charged precursor ion (data not shown). It can be seen from Figure 8a that the relative abundance of the neutral loss product ion resulting from dissociation of the $\mathrm{D}_{6}$-light labeled phosphopeptide is lower than the expected value. This is due to the presence of a $\mathrm{D}_{5}$-light DMBNHS impurity resulting from the use of a 98 atom \%D labeled $\gamma$-butyrolactone- $\mathrm{d}_{6}$ starting material for our synthesis. Although a kinetic isotope effect on the fragment ion yields associated with the "light" and "heavy" dimethylsulfide loss could also potentially contribute to this discrepancy, fragmentation efficiencies regarding $\mathrm{D}_{6}$-light and $\mathrm{D}_{6}$-heavy DMBNHS and their differentially labeled peptides were not systematically examined in this study, However, after taking into account the presence of the impurity, the correct relative abundance of the $\mathrm{S}\left(\mathrm{CH}_{3}\right)_{2}$ neutral loss product ion could be readily determined. It is known that using deuterated isotope labels can cause some chromatographic separation of "light" and "heavy" labeled peptides [72], potentially resulting in deviations to quantitative analysis depending on the time point across the chromatographic peak at which a given precursor ion is selected for analysis. However, the use of isobaric deuterated reagents should diminish or eliminate any shift in retention time of labeled peptides during LC separation. In the current study, some of the $\mathrm{D}_{6}$-light labeled peptides were observed to elute slightly earlier than their $\mathrm{D}_{6}$-heavy labeled counterparts, but, the

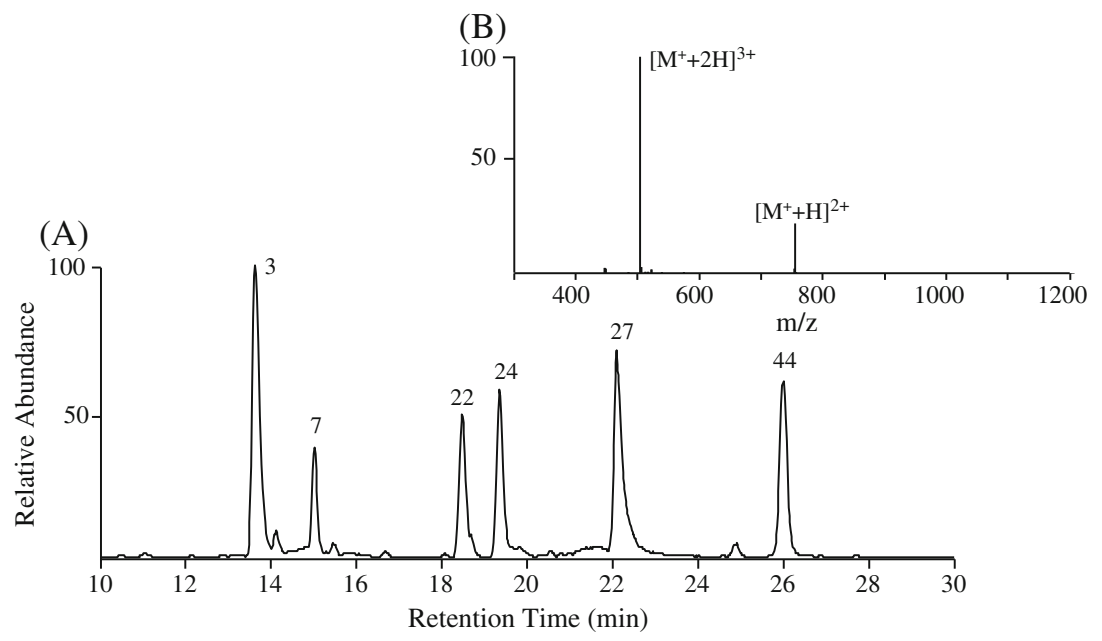

Figure 7. RP-HPLC ESI-MS analysis of $\mathrm{D}_{6}$-light DMBNHS and $\mathrm{D}_{6}$-heavy DMBNHS differentially labeled phosphopeptides. (A) Base peak chromatogram of a representative 6-phosphopeptide mixture differentially labeled with $\mathrm{D}_{6}$-light $\mathrm{DMBNHS}$ and $\mathrm{D}_{6}{ }^{-}$ heavy DMBNHS at a ratio of 1:1. The sequence of each phosphopeptide is listed in Table S1. (B) Mass spectrum obtained by ESI analysis of the singly derivatized phosphopeptide no. 27 (LFTGHPEpSLER) 

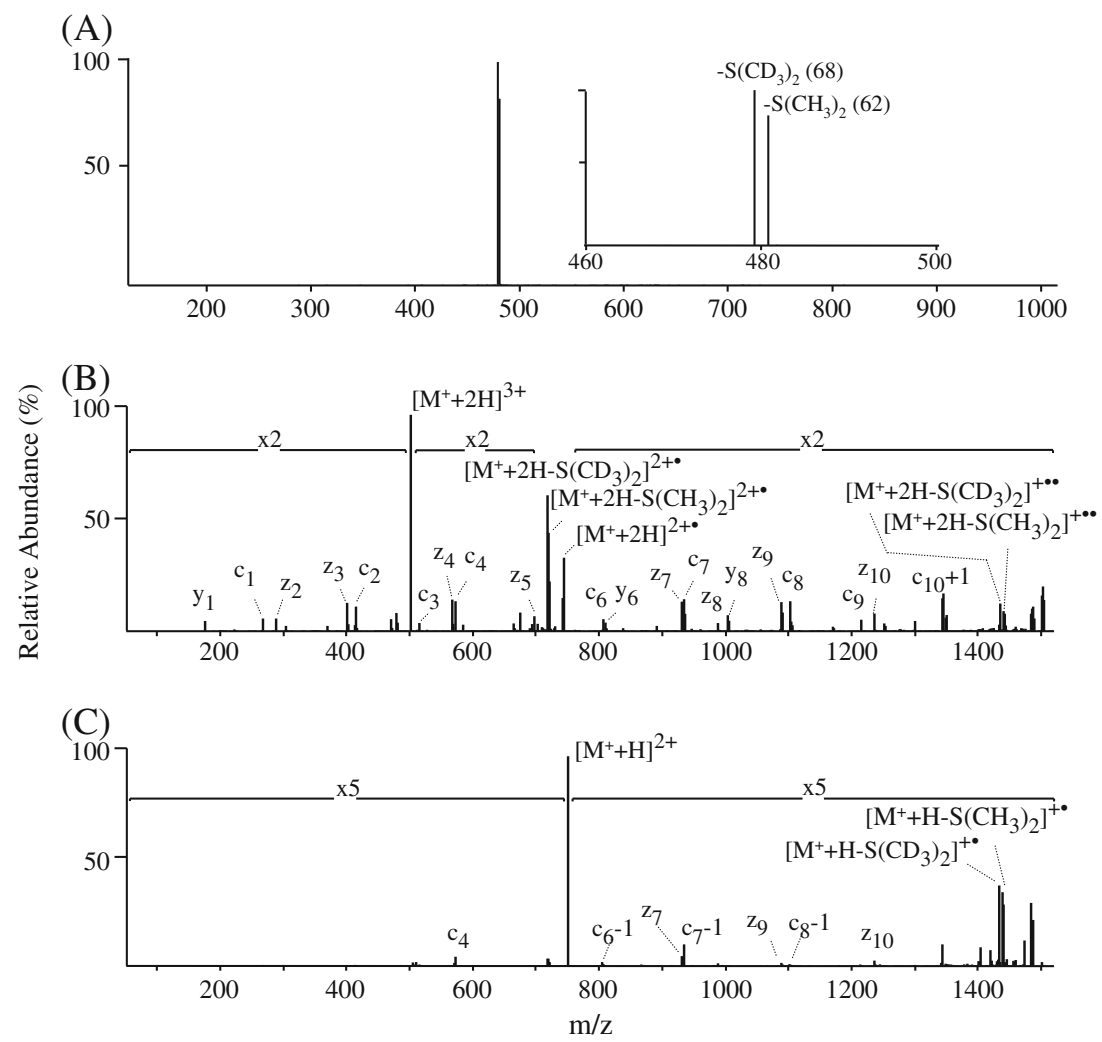

Figure 8. CID- and ETD-MS/MS analysis of phosphopeptide no. 27 (LFTGHPEpSLER) differentially labeled with $\mathrm{D}_{6}$-light DMBNHS and $\mathrm{D}_{6}$-heavy DMBNHS at a ratio of 1:1. (A) CID-MS/MS of the $\left[\mathrm{M}^{+}+2 \mathrm{H}\right]^{3+}$ precursor ion. The inset shows an expanded $\mathrm{m} / \mathrm{z}$ region around the observed exclusive $\mathrm{S}\left(\mathrm{CH}_{3}\right)_{2}$ and $\mathrm{S}\left(\mathrm{CD}_{3}\right)_{2}$ neutral loss product ions. (B) ETD-MS/MS of the $\left[\mathrm{M}^{+}+2 \mathrm{H}\right]^{3+}$ precursor ion. (C) ETD-MS/MS of the $\left[\mathrm{M}^{+}+\mathrm{H}\right]^{2+}$ precursor ion

effect of this on accurate quantification was minimized by simply averaging all the CID-MS/MS scans (repeat count=5) that were acquired for a given precursor ion across each chromatographic peak. Following analysis of the various mixtures of light- and heavy-labeled phosphopeptide no. 27 , from both its $3+$ and $2+$ precursor ion charge states, a linear relationship $\left(\mathrm{R}^{2}=0.9999\right)$ between the measured and expected ratios $(5: 1,5: 1,2: 1,1: 1,1: 2$, and 1:5) was obtained (see Supplementary Figure S4). Indeed, for each of the six differentially labeled phosphopeptides in the mixture, an excellent agreement between measured and expected values was obtained. A plot showing the average ratio for all peptides, determined from both their $3+$ and $2+$ charge states, is shown in Supplementary Figure S5 $\left(\mathrm{R}^{2}=0.9986\right)$. Note that although 3+ charge states were observed for all the peptides upon DMBNHS labeling, the most abundant charge state for peptides no. 3, 22, 24 , and 44 remained 2+; hence these ions provided the greatest sensitivity for quantification in these cases.

Consistent with the results obtained by ETD-MS/MS of the natural abundance DMBNHS labeled phosphopeptides, the ETD-MS/MS spectra of the triply charged singly labeled phosphopeptide no. 27 provided a clear series of z- and c-type product ions from which the peptide sequence and site of phosphorylation could be readily and unambiguously determined, as well as moderately abundant neutral losses of $\mathrm{S}$
$\left(\mathrm{CH}_{3}\right)_{2}$ and $\mathrm{S}\left(\mathrm{CD}_{3}\right)_{2}$ from the charge reduced intact doubly and singly charged precursor ions (Figure $8 \mathrm{~b}$ ). An abundance ratio of 0.99:1 was measured from these ions (after correction for the presence of the $\mathrm{D}_{5}$-light DMBNHS impurity), which is very close to the expected ratio of $1: 1$, suggesting that ETDgenerated sulfonium ion tag specific neutral loss product ions may also be used for quantitative analysis. Similarly, although ETD-MS/MS of the doubly charged singly labeled phosphopeptide no. 27 (Figure 8c) provided only limited sequence information due to its poor dissociation efficiency, quantitative information regarding the ratio of light- to heavy-labeled peptide could readily be obtained (1.02:1) by measuring the abundances of the diagnostic $\mathrm{S}\left(\mathrm{CH}_{3}\right)_{2}$ and $\mathrm{S}\left(\mathrm{CD}_{3}\right)_{2}$ neutral loss product ions. From the data obtained by ETD-MS/MS of the +3 and +2 charge states, a linear relationship between the measured and expected ratios $\left(\mathrm{R}^{2}=0.9999\right)$ was obtained, comparable to that determined from the CID-MS/MS experiments (Supplementary Figure S6). Thus, the use of ETD-MS/ MS alone can provide simultaneous identification and relative quantification of phosphopeptides without need for prior CIDMS/MS, However, it is expected that this would be a less sensitive approach for quantification compared that obtained using CID, due to only a fraction of the precursor ion abundance being directed toward the required sulfonium ion specific neutral loss fragmentation pathway, particularly for 
higher charge state precursor ions. Therefore, for future studies involving the application of these reagents to large-scale phosphoproteome analysis, a dual ion activation strategy is recommended whereby ion trap CID-MS/ MS is first used for phosphopeptide quantification, followed by ETD-MS/MS for sequence identification and phosphorylation site characterization.

\section{Conclusions}

The results described here demonstrate that the introduction of fixed charge sulfonium ion moieties to the primary amine groups ( $\mathrm{N}$-termini and lysine side chains) of phosphopeptides leads to improved ionization efficiencies and increased and/or higher abundance charge state precursor ions. Upon CID-MS/MS, exclusive neutral loss(es) of dimethylsulfide are observed, independently of the proton mobility of the phosphopeptide, while keeping the phosphate group(s) intact. The relative abundances of 'light' versus 'heavy' neutral loss product ions from isobaric stable isotope encoded DMBNHS labeled phosphopeptides during CIDMS/MS or ETD-MS/MS enables differential quantitative analysis, whereas subsequent ETD-MS/MS of the intact precursor ion(s) allows phosphopeptide sequence identification and phosphorylation site characterization. In comparison to other derivatization methods, the DMBNHS labeling approach has the advantage of neutral loss specificity during collision induced gas-phase fragmentation along with an enhanced quantitation capability using both CID-MS/MS and ETD-MS/MS techniques. These results are therefore highly suggestive of the great potential of this reagent for further applied studies involving large scale quantitative analysis or protein post-translational modifications.

\section{Acknowledgments}

The authors acknowledge that support for this work was provided by funding from the National Science Foundation (CAREER: CHE-0547940).

\section{References}

1. Mann, M., Ong, S.-E., Grønborg, M., Steen, H., Jensen, O.N., Pandey, A.: Analysis of protein phosphorylation using mass spectrometry: Deciphering the phosphoproteome. Trends Biotechnol. 20, 261-226 (2002)

2. Reinders, J., Sickmann, A.: State-of-the-art in phosphoproteomics. Proteomics 5, 4052-4061 (2005)

3. Paradela, A., Albar, J.P.: Advances in the analysis of protein phosphorylation. J. Proteome Res. 7, 1809-1818 (2008)

4. Nita-Lazar, A., Saito-Benz, H., White, F.M.: Quantitative phosphoproteomics by mass spectrometry: Past, present, and future. Proteomics $\mathbf{8}$, 4433-4443 (2008)

5. Thingholm, T.E., Jensen, O.N., Larsen, M.R.: Analytical strategies for phosphoproteomics. Proteomics 9, 1451-1468 (2009)

6. Grimsrud, P.A., Swaney, D.L., Wenger, C.D., Beauchene, N.A., Coon, J.J.: Phosphoproteomics for the masses. ACS Chem. Biol. 5, 105-119 (2010)
7. Dunn, J.D., Reid, G.E., Bruening, M.L.: Techniques for phosphopeptide enrichment prior to analysis by mass spectrometry. Mass Spectrom. Rev. 29, 29-54 (2010)

8. Boersema, P.J., Mohammed, S., Heck, A.J.: Phosphopeptide fragmentation and analysis by mass spectrometry. J. Mass Spectrom. 44, 861878 (2009)

9. Palumbo, A.M., Smith, S.A., Kalcic, C.L., Dantus, M., Stemmer, P.M., Reid, G.E. Tandem mass spectrometry strategies for phosphoproteome analysis. Mass Spectrom. Rev. in press. doi:10.1002/mas.20310. (2011)

10. Annan, R.S., Carr, S.A.: Phosphopeptide analysis by matrix-assisted laser desorption time-of-flight mass spectrometry. Anal. Chem. 68, 3413-3421 (1996)

11. Palumbo, A.M., Tepe, J.J., Reid, G.E.: Mechanistic insights into the multistage gas-phase fragmentation behavior of phosphoserine- and phosphothreonine-containing peptides. J. Proteome Res. 7, 771-779 (2008)

12. Palumbo, A.M., Reid, G.E.: Evaluation of gas-phase rearrangement and competing fragmentation reactions on protein phosphorylation site assignment using CID-MS/MS and MS ${ }^{3}$. Anal. Chem. 80, 9735-9747 (2008)

13. Schlosser, A., Pipkorn, R., Bossemeyer, D., Lehmann, W.D.: Analysis of protein phosphorylation by combination of elastase digest and neutral loss tandem mass spectrometry. Anal. Chem. 73, 170-176 (2001)

14. Chang, E.J., Archambault, V., McLachlin, D.T., Krutchinsky, A.N., Chait, B.T.: Analysis of protein phosphorylation by hypothesis-driven multiple-stage mass spectrometry. Anal. Chem. 76, 4472-4483 (2004)

15. Schroeder, M.J., Shabanowitz, J., Schwartz, J.C., Hunt, D.F., Coon, J.J.: A neutral loss activation method for improved phosphopeptide sequence analysis by quadrupole ion trap mass spectrometry. Anal. Chem. 76, 3590-3598 (2004)

16. Beausoleil, S.A., Villén, J., Gerber, S.A., Rush, J., Gygi, S.P.: A probability-based approach for high-throughput protein phosphorylation analysis and site localization. Nat. Biotechnol. 24, 1285-1292 (2006)

17. Olsen, J.V., Blagoev, B., Gnad, F., Macek, B., Kumar, C., Mortensen, P., Mann, M.: Global, in vivo, and site-specific phosphorylation dynamics in signaling networks. Cell 127, 635-648 (2006)

18. Ulintz, P.J., Yocum, A.K., Bodenmiller, B., Aebersold, R., Andrews, P. C., Nesvizhskii, A.: Comparison of MS(2)-only, MSA, and MS(2)/MS (3) methodologies for phosphopeptide identification. J. Proteome Res. 8, 887-899 (2009)

19. Syka, J.E.P., Coon, J.J., Schroeder, M.J., Shabanowitz, J., Hunt, D.F.: Peptide and protein sequence analysis by electron transfer dissociation mass spectrometry. Proc. Natl. Acad. Sci. U.S.A. 101, 9528-9533 (2004)

20. Wiesner, J., Premsler, T., Sickmann, A.: Application of electron transfer dissociation (ETD) for the analysis of posttranslational modifications. Proteomics 8, 4466-4483 (2008)

21. Good, D.M., Wirtala, M., McAlister, G.C., Coon, J.J.: Performance evaluation of electron transfer dissociation. Mol. Cell. Proteomics 6, 1942-1951 (2007)

22. Molina, H., Horn, D.M., Tang, N., Mathivanan, S., Pandey, A.: Global proteomic profiling of phosphopeptides using electron transfer dissociation tandem mass spectrometry. Proc. Natl. Acad. Sci. U.S.A. 104, 2199-2204 (2007)

23. Swaney, D.L., McAlister, G.C., Coon, J.J.: Decision tree-driven tandem mass spectrometry for shotgun proteomics. Nat. Method 5, 959-964 (2008)

24. Swaney, D.L., Wenger, C.D., Thomson, J.A., Coon, J.J.: Human embryonic stem cell phosphoproteome revealed by electron transfer dissociation tandem mass spectrometry. Proc. Natl. Acad. Sci. U.S.A. 106, 995-1000 (2009)

25. Deng, N., Zhang, J., Zong, C., Wang, Y., Lu, H., Yang, P., Wang, W., Young, G. W., Wang, Y., Korge, P., Lotz, C., Doran, P., Liem, D.A., Apweiler, R., Weiss, J.N., Duan, H., Ping, P. Phosphoproteome analysis reveals regulatory sites in major pathways of cardiac mitochondria. Mol. Cell. Proeomt. in press. doi: 10.1074/mcp.M110.000117. (2011)

26. Bonewald, L.F., Bibbs, L., Kates, S.A., Khatri, A., McMurray, J.S., Medzihradszky, K.F., Weintraub, S.T.: Study on the synthesis and characterization of peptides containing pY. J. Peptide Res. 53, 161-169 (1999)

27. Janek, K., Wenschuh, H., Bienert, M., Krause, E.: Phosphopeptide analysis by positive and negative ion MALDI MS. Rapid Commun. Mass Spectrom. 15, 1593-1599 (2001)

28. Gropengiesser, J., Varadarajan, B.T., Stephanowitz, H., Krause, E.: The relative influence of phosphorylation and methylation on responsiveness of peptides to MALDI and ESI mass spectrometry. J. Mass Spectrom. 44, 821-831 (2009) 
29. Steen, H., Jebanathirajah, J.A., Rush, J., Morrice, N., Kirschner, M.W.: Phosphorylation analysis by mass spectrometry: Myths, facts, and the consequences for qualitative and quantitative measurements. Mol. Cell. Proteom. 5, 172-181 (2006)

30. Chi, A., Huttenhower, C., Geer, L.Y., Coon, J.J., Syka, J.E.P., Bai, D. L., Shabanowitz, J., Burke, D.J., Troyanskaya, O.G., Hunt, D.F.: Analysis of phosphorylation sites on proteins from Saccharomyces cerevisiae by electron transfer dissociation (ETD) mass spectrometry. Proc. Natl. Acad. Sci. U.S.A. 104, 2193-2198 (2007)

31. Taouatas, N., Drugan, M.M., Heck, A.J.R., Mohammed, S.: Straightforward ladder sequencing of peptides using a Lys-N metalloendopeptidase. Nat. Methods 5, 405-407 (2008)

32. Kjeldsen, F., Giessing, A., Ingrell, C.R., Jensen, O.N.: Peptide sequencing and characterization of post-translational modifications by enhanced ion-charging and liquid chromatography electron-transfer dissociation tandem mass spectrometry. Anal. Chem. 79, 9243-9252 (2007)

33. Lomeli, S.H., Peng, I.X., Yin, S., Ogorzalek Loo, R.R., Loo, J.A.: New reagents for increasing ESI multiple charging of proteins and protein complexes. J. Am. Soc. Mass Spectrom. 21, 127-131 (2010)

34. Leitner, A., Lindner, W.: Chemistry meets proteomics: the use of chemical tagging reactions for MS-based proteomics. Proteomics 6 , 5418-5434 (2006)

35. Leitner, A., Lindner, W.: Chemical tagging strategies for mass spectrometry-based phospho-proteomics. Methods Mol. Biol. 527, 229-243 (2009)

36. Mirzaei, H., Regnier, F.: Enhancing electrospray ionization efficiency of peptides by derivatization. Anal. Chem. 78, 4175-4183 (2006)

37. Vasicek, L., Brodbelt, J.S.: Enhanced electron transfer dissociation through fixed charge derivatization of cysteines. Anal. Chem. 81, 78767884 (2009)

38. Madsen, J.A., Brodbelt, J.S.: Simplifying fragmentation patterns of multiply charged peptides by N-terminal derivatization and electron transfer collision activated dissociation. Anal. Chem. 81, 3645-3653 (2009)

39. Xu, Y., Zhang, L., Lu, H., Yang, P.: Mass spectrometry analysis of phosphopeptides after peptide carboxy group derivatization. Anal. Chem. 80, 8324-8328 (2008)

40. Zhang, L., Xu, Y., Lu, H., Yang, P.: Carboxy group derivatization for enhanced electron-transfer dissociation mass spectrometric analysis of phosphopeptides. Proteomics 9, 4093-4097 (2009)

41. Hennrich, M.L., Boersema, P.J., van den Toorn, H., Mischerikow, N., Heck, A.J., Mohammed, S.: Effect of chemical modifications on peptide fragmentation behavior upon electron transfer induced dissociation. Anal. Chem. 81, 7814-7822 (2009)

42. Ross, P.L., Huang, Y.N., Marchese, J.N., Williamson, B., Parker, K., Hattan, S., Khainovski, N., Pillai, S., Dey, S., Daniels, S., Purkayastha, S., Juhasz, P., Martin, S., Bartlet-Jones, M., He, F., Jacobson, A., Pappin, D.J.: Multiplexed protein quantitation in Saccharomyces cerevisiae using amine-reactive isobaric tagging reagents. Mol. Cell. Proteom. 4, 1154-1169 (2004)

43. Thompson, A., Schäfer, J., Kuhn, K., Kienle, S., Schwarz, J., Schmidt, G., Neumann, T., Hamon, C.: Tandem mass tags: a novel quantification strategy for comparative analysis of complex protein mixtures by MS/ MS. Anal. Chem. 75, 1895-1904 (2003)

44. Phanstiel, D., Unwin, R., McAlister, G.C., Coon, J.J.: Peptide quantification using 8-plex isobaric tags and electron transfer dissociation tandem mass spectrometry. Anal. Chem. 81, 1693-1698 (2009)

45. Sachon, E., Mohammed, S., Bache, N., Jensen, O.N.: Phosphopeptide quantitation using amine-reactive isobaric tagging reagents and tandem mass spectrometry: application to proteins isolated by gel electrophoresis. Rapid Commun. Mass Spectrom. 20, 1127-1134 (2006)

46. Viner, R.I., Zhang, T., Second, T., Zabrouskov, V.: Quantification of post-translationally modified peptides of bovine $\alpha$-crystalline using tandem mass tags and electron transfer dissociation. J. Proteoms. 72, 874-885 (2009)

47. Nilsson, C.L., Dillon, R., Devakumar, A., Shi, S.D., Greig, M., Rogers, J.C., Krastins, B., Rosenblatt, M., Kilmer, G., Major, M., Kaboord, B.J., Sarracino, D., Rezai, T., Prakash, A., Lopez, M., Ji, Y., Priebe, W., Lang, F.F., Colman, H., Conrad, C.A.: Quantitative phosphoproteomic analysis of the STAT3/IL-6/HIF1 $\alpha$ signaling network: An initial study in GSC11 glioblastoma stem cells. J. Proteome Res. 9, 430-443 (2010)

48. Thingholm, T.E., Palmisano, G., Kjeldsen, F., Larsen, M.R.: Undesirable charge-enhancement of isobaric tagged phosphopeptides leads to reduced identification efficiency. J. Prot. Res. 9, 4045-4052 (2010)
49. Pichler, P., Köcher, T., Holzmann, J., Mazanek, M., Taus, T., Ammerer, G., Mechtler, K.: Peptide labeling with isobaric tags yields higher identification rates using iTRAQ 4-plex compared to TMT 6-plex and iTRAQ 8-plex on LTQ Orbitrap. Anal. Chem. 82, 6549-6558 (2010)

50. Bantscheff, M., Boesche, M., Eberhard, D., Matthieson, T., Sweetman, G., Kuster, B.: Robust and sensitive iTRAQ quantification on an LTQ Orbitrap mass spectrometer. Mol. Cell. Proteom. 7, 17021713 (2008)

51. Yang, F., Wu, S., Stenoien, D.L., Zhao, R., Monroe, M.E., Gritsenko, M.A., Purvine, S.O., Polpitiya, A.D., Tolić, N., Zhang, Q., Norbeck, A.D., Orton, D.J., Moore, R.J., Tang, K., Anderson, G. A., Pasa-Tolić, L., Camp, D.G., Smith, R.D.: Combined pulsed-Q dissociation and electron transfer dissociation for identification and quantification of iTRAQ-labeled phosphopeptides. Anal. Chem. 81, 4137-4143 (2009)

52. Han, H., Pappin, D.J., Ross, P.L., McLuckey, S.A.: Electron transfer dissociation of iTRAQ labeled peptide ions. J. Proteome Res. 7, 36433648 (2008)

53. Phanstiel, D., Zhang, Y., Marto, J.A., Coon, J.J.: Peptide and protein quantification using iTRAQ with electron transfer dissociation. $J . \mathrm{Am}$. Soc. Mass Spectrom. 19, 1255-1262 (2008)

54. Mischerikow, N., van Nierop, P., Li, K.W., Bernstein, H.G., Smit, A.B., Heck, A.J., Altelaar, A.F.: Gaining efficiency by parallel quantification and identification of iTRAQ-labeled peptides using HCD and decision tree guided CID/ETD on an LTQ Orbitrap. Analyst 135, 2643-2652 (2010)

55. Boja, E.S., Phillips, D., French, S.A., Harris, R.A., Balaban, R.S.: Quantitative mitochondrial phosphoproteomics using iTRAQ on an LTQ-Orbitrap with high energy collision dissociation. J. Proteome Res. 8, 4665-4675 (2009)

56. Reid, G.E., Roberts, K.D., Simpson, R.J., O'Hair, R.A.J.: Selective Identification and quantitative analysis of methionine containing peptides by charge derivatization and tandem mass spectrometry. $J$. Am. Soc. Mass Spectrom. 16, 1131-1150 (2005)

57. Froelich, J.M., Kaplinghat, S., Reid, G.E.: Automated neutral loss

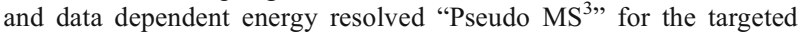
identification, characterization, and quantitative analysis of methionine-containing peptides. Eur. J. Mass Spectrom. 14, 219-229 (2008)

58. Amunugama, M., Roberts, K.D., Reid, G.E.: Mechanisms for the selective gas-phase fragmentation reactions of methionine side chain fixed charge sulfonium ion containing peptides. J. Am. Soc. Mass Spectrom. 17, 1631-1642 (2006)

59. Roberts, K.D., Reid, G.E.: Leaving group effects on the selective gas phase fragmentation reactions of cysteine side chain fixed charge containing peptide ions. J. Mass Spectrom. 42, 187-198 (2007)

60. Zhou, X., Lu, Y., Wang, W., Borhan, B., Reid, G.E.: 'Fixed charge' Chemical derivatization and data dependant multistage tandem mass spectrometry for mapping protein surface residue accessibility. J. Am. Soc. Mass Spectrom. 21, 1339-1351 (2010)

61. Lu, Y., Tanasova, M., Borhan, B., Reid, G.E.: An ionic reagent for controlling the gas-phase fragmentation reactions of cross-linked peptides. Anal. Chem. 80, 9279-9287 (2008)

62. Jessing, M., Brandt, M., Jensen, K.J., Christensen, J.B., Boas, U.J.: Org. Chem. 71, 6734-6741 (2006)

63. Crouch, N.P., Adlington, R.M., Baldwin, J.E., Lee, M.-H., MacKinnon, C.H.: Tetrahedron 53, 6993-7010 (1997)

64. Kulevich, S.E., Frey, B.L., Kreitinger, G., Smith, L.M.: Alkylating tryptic peptides to enhance electrospray ionization mass spectrometry analysis. Anal. Chem. 82, 10135-10142 (2010)

65. Krokhin, O.V., Craig, R., Spicer, V., Ens, W., Standing, K.G., Beavis, R.C., Wilkins, J.A.: Mol. Cell. Proteom. 3, 908-919 (2004)

66. Frahm, J.L., Bori, I.D., Comins, D.L., Hawkridge, A.M., Muddiman, D. C.: Achieving augmented limits of detection for peptides with hydrophobic alkyl tags. Anal. Chem. 79, 3989-3995 (2007)

67. Hohmann, L.J., Eng, J.K., Gemmill, A., Klimek, J., Vitek, O., Reid, G. E., Martin, D.B.: Quantification of the compositional information provided by immonium ions on a quadrupole-TOF mass spectrometer. Anal. Chem. 80, 5596-5606 (2008)

68. Xia, Q.W., Lee, M.V., Rose, C.M., Marsh, A.J., Hubler, S.L., Wenger, C.D., Coon, J.J.: Characterization and diagnostic value of amino acid side chain neutral losses following electron-transfer dissociation. J. Am. Soc. Mass Spectrom. 22, 255-264 (2011) 
69. Li, X., Cournoyer, J.J., Lin, C., O'Connor, P.B.: The effect of fixed charge modifications on electron capture dissociation. J. Am. Soc. Mass Spectrom. 19, 1514-1526 (2008)

70. Chamot-Rooke, J., van der Rest, G., Dalleu, A., Bayc, S., Lemoineb, J.: The combination of electron capture dissociation and fixed charge derivatization increases sequence coverage for O-glycosylated and O-phosphorylated peptides. J. Am. Soc. Mass Spectrom. 18, 1405-1413 (2007)
71. Swaney, D.L., McAlister, G.C., Wirtala, M., Schwartz, J.C., Syka, J.E. P., Coon, J.J.: Supplemental activation method for high-efficiency electron-transfer dissociation of doubly protonated peptide precursors. Anal. Chem. 79, 477-485 (2007)

72. Zhang, R., Regnier, F.E.: Minimizing resolution of isotopically coded peptides in comparative proteomics. J. Proteome Res. 1, 139147 (2002) 